\title{
LOS ELEMENTOS DE LA COMPETENCIA JURISDICCIONAL*
}

\author{
JORGE SÁEZ MARTIN**
}

\begin{abstract}
RESUMEN: El presente estudio trata de los factores que determinan la manera en que se distribuye la competencia de los tribunales en el ordenamiento jurídico chileno, y busca demostrar que los que tradicionalmente se enseñan como tales por la doctrina nacional, a saber: la persona o fuero, la materia y la cuantía, resultan insuficientes para explicar esa distribución. Así, a la luz de la doctrina comparada y de las normas particulares de nuestro ordenamiento procesal plantea la existencia de otros factores que permiten explicar la forma en que se distribuye la competencia. Finalmente, cuestiona la significación que la doctrina nacional ha dado a la clasificación entre competencia relativa y absoluta, explicando el significado que se atribuye en el derecho comparado y su consecuencia en la clasificación que se hace de los criterios de competencia, en especial, del territorio.
\end{abstract}

PALABRAS CLAVE: Competencia - juez natural - factores de competencia - competencia absoluta - competencia relativa.

\section{THE ELEMENTS OF JURISDICTION}

ABSTRACT: This study deals with the elements that determine jurisdiction of the Chilean legal courts. It addresses the explanations of legal scholars about those elements, considering then as insufficient. Exploring a comparative point of view and using the framework of our national procedural rules, it is presented other jurisdiction's criteria. Finally, this study discusses the traditional perspective used by national legal research that classifies competence between an absolute and a relative one.

KEY WORDS: Competence - jurisdiction - competence elements - absolute competence - relative competence.

Fecha de recepción: 11 de junio de 2013.

Fecha de aceptación: 25 de febrero de 2015.

** Licenciado en Derecho de la Pontificia Universidad Católica de Chile (Chile); profesor de Derecho Procesal de la Facultad de Derecho de la Universidad Alberto Hurtado (CHILE) y Juez de Garantía de Santiago de Chile. 
Sumario: 1) La necesidad de los elementos de la competencia. 2) La materia, fuero, cuantía y territorio. 3) Los otros elementos de la competencia. (3.1.) El grado. (3.2.) El turno. (3.3.) La atracción. (3.4.) La conexidad. (3.5.) La elección. (3.6.) El azar. (3.7.) El tiempo o época en que ocurren los hechos. (3.8.) El procedimiento. (3.8.1.) Planteamiento de la cuestión. (3.8.2.) Ámbito Civil. (3.8.3.) Ámbito Penal. (3.8.4.) Ámbito Laboral y Previsional. (3.9.) La prevención. 4) Competencia absoluta y relativa. 5) Conclusiones.

\section{1) LA NECESIDAD DE LOS ELEMENTOS DE LA COMPETENCIA}

Muchas definiciones se han propuesto para el concepto de competencia. Para el solo objeto de introducir este análisis me permito citar la definición que daba Rocco, para quien la competencia "Es aquella parte de jurisdicción que corresponde en concreto a cada órgano jurisdiccional singular, según ciertos criterios a través de los cuales las normas procesales distribuyen la jurisdicción entre los distintos órganos ordinarios de ella"1.

El Código Orgánico de Tribunales contempla en el artículo 108 una definición de competencia al señalar que "La competencia es la facultad que tiene cada juez o tribunal para conocer de los negocios que la ley ha colocado dentro de la esfera de sus atribuciones".

Si solo existiera un tribunal en todo el territorio de la República para resolver todas las cuestiones que se presenten, el concepto de competencia se confundiría con el de jurisdicción y su análisis sería absolutamente innecesario. Pero este supuesto está alejado de la realidad, que demanda la existencia de diversos órganos habilitados para ejercer la jurisdicción ya sea por la complejidad de los asuntos que se deben resolver; la extensión de los territorios en que se debe ejercer la función, para permitir el acceso a la justicia de todas las personas; la necesidad de velar por los derechos fundamentales que exigen la existencia de tribunales con poder para revisar las decisiones de otros y ante los cuales reclamar las decisiones dictadas que afectan los intereses de las partes; la necesidad de velar por cargas de trabajo adecuadas que permitan resolver los asuntos en el tiempo oportuno; etc.

De tal manera que en los distintos ordenamientos jurídicos nacionales nos encontramos con una diversidad de tribunales dispuestos para resolver las cuestiones que la ley les encomienda.

Se hace necesario, en consecuencia, fijar los criterios conforme a los cuales la ley distribuye el ejercicio de la jurisdicción entre los tribunales

Rocco, Ugo (2002): Derecho Procesal Civil. Ciudad de México: Editorial Jurídica Universitaria, p. 246. 
establecidos por ella. A estos criterios se les llama elementos o factores de la competencia ${ }^{2}$.

La cuestión del tribunal competente o de la predeterminación legal del juez está estrechamente ligada a los derechos fundamentales. En efecto, todas las normas de competencia están vinculadas con el resguardo del derecho al juez predeterminado, derecho que está consagrado en la propia Constitución en el artículo $19 \mathrm{~N}^{\circ} 3$, inciso $4^{\circ}$, que dispone que "Nadie podrá ser juzgado por comisiones especiales, sino por el tribunal que señalare la ley y que se hallare establecido por esta con anterioridad a la perpetración del hecho" 3 .

De la norma citada emana la exigencia para que el legislador contemple las reglas conforme a las cuales se distribuirá el ejercicio de la jurisdicción entre los diversos tribunales del país de modo de resguardar que todo ciudadano será juzgado por el Tribunal que fija la ley con anterioridad a la ocurrencia del hecho que origina el conflicto y no por otro distinto. El juez natural "impone la inderogabilidad y la indisponibilidad de las competencias, esto es, la reserva absoluta de ley y la no alterabilidad discrecional de las competencias judiciales" ${ }^{4}$, lo cual significa que debe estar establecida con caracteres de objetividad y generalidad tales que impidan a la autoridad, cualquiera que sea, la posibilidad de crear o modificar el tribunal que ha de conocer el asunto.

Tratándose del juez natural, por lo tanto, existen varias exigencias que se pueden enunciar como las siguientes:

1) El órgano debe haber sido creado por ley. Este requisito es uno de los que el Tribunal Constitucional de España ha señalado como exigen-

2 Redenti, Enrico (1957) Derecho Procesal Civil, T. I. Buenos Aires: Ediciones Jurídicas Europa-América, p. 141, lo plantea en los siguientes términos: "A determinar la esfera de competencia de cada uno (de los tribunales) concurren diversos órdenes de criterios, y por tanto de reglas legales concurrentes y coordenadas entre sí, de tal modo, que toda posible causa, práctica $o$ asunto, encuentre por lo menos un juez (o también más de uno, a elección de los interesados) competente para examinar, decidir y proveer, y que a todo juez dé una conveniente esfera de actividades posibles. Todo ello, naturalmente, siempre que haya jurisdicción de la autoridad judicial. Lo cual, invirtiendo los términos, quiere también decir que, donde no se pueda identificar a un juez competente, no hay jurisdicción".

3 El artículo $2^{\circ}$ del Código Procesal Penal, en los mismos términos dispone: "Artículo $2^{\circ}$.Juez natural. Nadie podrá ser juzgado por comisiones especiales, sino por el tribunal que señalare la ley y que se hallare establecido por ésta con anterioridad a la perpetración del hecho".

4 Corte Interamericana de Derechos Humanos, 30 de mayo de 1999. "Castillo Petruzzi y otros vs. Perú”. Disponible en http://www.corteidh.or.cr/docs/casos/articulos/seriec_52_esp. pdf [fecha de visita 22 de diciembre de 2014] p. 44. Estas expresiones están citadas en el fallo al reproducir los argumentos planteados por la Comisión Interamericana de Derechos Humanos, por lo que no constituyen una afirmación de la propia Corte, aunque algunos autores han sostenido lo contrario. Ver al efecto: Caballero, Ana Isabel, y Stippel, Jörg (2003): "Parte II. Jurisprudencia”, en Defensoría Penal Pública (edit.), Manual de Derecho Internacional de los Derechos Humanos para Defensores Penales Públicos. Santiago de Chile: Centro de Documentación Defensoría Penal Pública, p. 144. 
cia del derecho al Juez ordinario predeterminado por la Ley 5 . Se contempla expresamente en la Constitución (artículo 76); en la Convención Americana de Derechos Humanos (artículo 8.1); y, en el Pacto Internacional de Derechos Civiles y Políticos (artículo 14).

2) El órgano debe existir antes de la ocurrencia del hecho que origina el conflicto. Este requisito se contempla expresamente en la Constitución (artículo $19 \mathrm{~N}^{\circ} 3$, inciso quinto); en la Convención Americana de Derechos Humanos (artículo 8.1); y, en el Pacto Internacional de Derechos Civiles y Políticos (artículo 14).

3) El órgano que debe conocer del asunto debe tener jurisdicción. Esto, que puede parecer una obviedad, dice relación con que su finalidad debe ser la aplicación del derecho, despojado de todo otro interés. Este también es un requisito declarado por el Tribunal Constitucional español.

4) El órgano debe estar dotado de competencia. Este requisito es un presupuesto procesal, es decir, un requisito de validez del proceso, pero además una garantía del justiciable consagrada en la Constitución (artículos $7^{\circ}$ y $19 \mathrm{~N}^{\circ} 3$, inciso quinto); en la Convención Americana de Derechos Humanos (artículo 8.1); y, en el Pacto Internacional de Derechos Civiles y Políticos (artículo 14).

5) La competencia del tribunal debe igualmente estar determinada antes de la ocurrencia de ese hecho. El Tribunal Constitucional chileno "declaró, en sentencia de 18 de enero de 1990 -causa Rol No 91 - en su considerando treinta, que la expresión "con anterioridad por esta" debía entenderse en el sentido de que el tribunal debía estar determinado con anterioridad a los hechos que se juzguen"6.

6) La competencia debe estar determinada por la ley. Este requisito se encuentra sancionado con claridad en el caso de Chile por el artículo $7^{\circ}$ de la Constitución. Montero Aroca explica que el requisito, para el caso español consiste en que "Existiendo varios órganos de la misma categoría en la población, han de existir normas objetivas de reparto; el reparto no precisa ley formal, pero sí de criterios objetivos, no discrecionales" por la doctrina chilena como distribución de causas. Desde luego no es pacífico que las reglas de distribución de causas no sean reglas de competencia y a ello me referiré más adelante, pero lo que es claro es

Sentencia Tribunal Constitucional de España 64/1997, 7 de abril de 1997. Boletín Oficial del Estado núm. 114 de 13 de mayo de 1997, pp. 15 a 20.

6 Vivanco Martínez, Angela (2006): Curso de Derecho Constitucional, Tomo II. Santiago de Chile: Ediciones Universidad Católica de Chile, p. 315.

7 Montero Aroca, Juan (2003): Derecho Jurisdiccional I. Parte General. T. I. Valencia: Editorial Tirant lo Blanch, p. 85. 
que, en el caso de Chile, los criterios de distribución, que han de ser objetivos y generales, deben estar contemplados por la ley.

7) No puede haber concurrencia de la competencia, esto es, no pueden haber dos o más tribunales igualmente competentes, lo que se traduce en que la ley debe contemplar las reglas conforme a las cuales el órgano jurisdiccional debe estar determinado o ser determinable. "La aplicación de las reglas de competencia debe llevar siempre a determinar a un juez natural, dentro de los varios que componen el órgano jurisdiccional" 8 .

8) "En la designación de la persona o personas concretas dotadas de jurisdicción que han de constituir el órgano, se ha de seguir el procedimiento legalmente establecido" 9 . Este requisito asume la realidad de que los órganos están constituidos por personas y que no hay un avance real en el resguardo de la garantía si se reemplazan las comisiones especiales por órganos jurisdiccionales permanentes, pero cuyos integrantes pueden ser nombrados o reemplazados discrecionalmente. El artículo 768 del Código de Procedimiento Civil, en su número 1, establece como una causal de casación en la forma "Cuando la sentencia hubiere sido pronunciada por un tribunal (...) no integrado por los jueces designados por la ley”. El artículo 374 del Código Procesal Penal contempla, dentro de los motivos absolutos de nulidad del juicio y la sentencia, en su letra a "Cuando la sentencia hubiere sido pronunciada por un tribunal (...) no integrado por los jueces designados por la ley".

9) Montero Aroca agrega como exigencia de la predeterminación del juez que existan normas de asignación de ponencias a los magistra$\operatorname{dos}^{10}$. El juez ponente en el sistema español tiene diversas funciones definidas en el artículo 205 de la Ley Orgánica del Poder Judicial ${ }^{11}$,

Romero Seguel, Alejandro (2009): Curso de Derecho Procesal Civil. Los presupuestos procesales relativos al órgano jurisdiccional. T. I. Santiago: Editorial Jurídica de Chile, p. 33.

Montero Aroca (2003) 85.

10 Montero Aroca (2003) 86.

11 El artículo 205 dispone "Corresponderá al ponente, en los pleitos o causas que le hayan sido turnadas:

1. El despacho ordinario y el cuidado de su tramitación.

2. Examinar los interrogatorios, pliegos de posiciones y proposición de pruebas presentadas por las partes e informar sobre su pertinencia.

3. Presidir la práctica de las pruebas declaradas pertinentes, siempre que no deban practicarse ante el Tribunal.

4. Informar los recursos interpuestos contra las decisiones de la Sala o Sección.

5. Proponer los autos decisorios de incidentes, las sentencias y las demás resoluciones que hayan de someterse a discusión de la Sala o Sección, y redactarlos definitivamente, si se conformase con lo acordado.

6. Pronunciar en Audiencia Pública las sentencias. 
entre las que se incluye la de redactor del fallo, siendo esta suficientemente relevante como para justificar hasta él la extensión de las reglas de predeterminación.

10) El tribunal no puede extender su decisión a cuestiones que no le hayan sido sometidas por las partes, a menos que esté facultado expresamente por la ley. El objeto del proceso genera un límite en la competencia del juez que denominamos competencia específica, que se expresa en el artículo 160 del Código de Procedimiento Civil en cuanto "Las sentencias se pronunciarán conforme al mérito del proceso, y no podrán extenderse a puntos que no hayan sido expresamente sometidos a juicio por las partes, salvo en cuanto las leyes manden o permitan a los tribunales proceder de oficio". Al respecto, la Corte Suprema ha resuelto que "entre los principios rectores del proceso-constituidos por ciertas ideas centrales referidas a su estructuración y que deben tomarse en cuenta tanto por el juez al tramitar y decidir las controversias sometidas a su conocimiento como por el legislador al sancionar las leyes- figura el de la congruencia, que sustancialmente se refiere a la conformidad que ha de existir entre la sentencia expedida por el órgano jurisdiccional y las pretensiones que las partes han expuesto oportuna y formalmente en sus escritos fundamentales agregados al proceso; se plasma en el brocárdico "ne eat iudex ultra petitia partium" y guarda estrecha vinculación con otro principio formativo del proceso: el dispositivo. (...) Que el principio procesal, a que se ha venido haciendo mención, tiende a "frenar a todo trance cualquier eventual exceso de la autoridad del oficio", otorgando garantía de seguridad y certeza a las partes; y se vulnera con la incongruencia que, en su faz objetiva "desde la perspectiva de nuestro ordenamiento procesal civil, se presenta bajo dos modalidades: ultra petita, cuando se otorga más de lo pedido por las partes, circunstancia que puede darse tanto respecto de la pretensión del demandante como de la oposición del demandado; y extra petita, cuando se concede algo que no ha sido impetrado, extendiéndose el pronunciamiento a cuestiones que no fueron sometidas a la decisión del tribunal"12.

11) El tribunal que dicta la sentencia sea el mismo que aquel que se avoca al conocimiento del asunto. Esta exigencia se resguarda en el artículo 768 del Código de Procedimiento Civil, que en su número 3, establece como una causal de casación en la forma "En haber sido acordada en los tribunales colegiados (...) con la concurrencia de jueces

12 Sentencia Corte Suprema. 30 de enero de 2014. Rol: 669-2013. Recurso de casación en la forma y en el fondo en causa "Paredes Ortega, María con Merino Paredes, Daniela Patricia”, considerandos $9^{\circ}$ y $11^{\circ}$. Disponible en http://suprema.poderjudicial.cl/SITSUPPORWEB/InicioAplicacion.do [fecha de visita 23 de diciembre de 2014]. 
que no asistieron a la vista de la causa, y viceversa”. El artículo 374 del Código Procesal Penal contempla, dentro de los motivos absolutos de nulidad del juicio y la sentencia, en su letra a, "Cuando la sentencia hubiere sido (...) acordada (...) con concurrencia de jueces que no hubieren asistido al juicio".

12) La existencia de mecanismos de reclamo frente al desconocimiento de cualquiera de estas exigencias.

El Tribunal Constitucional de España incluye dentro de las exigencias respecto del juez ordinario predeterminado por la ley, aquella que refiere a que "su régimen orgánico y procesal no permita calificarlo de órgano especial o excepcional" 13 . Dentro de esas exigencias se pueden considerar todas aquellas que dan garantías de su independencia e imparcialidad. Romero menciona específicamente la garantía de inamovilidad, la que considera "un complemento indispensable en la actuación del juez natural" 14 y que se encuentra consagrada en el artículo 80 de la Constitución Política al establecer que "Los jueces permanecerán en sus cargos durante su buen comportamiento; pero los inferiores desempeñarán su respectiva judicatura por el tiempo que determinen las leyes".

Junto a la inamovilidad, adquiere importancia la forma de selección de los jueces, por cuanto "Tanto la independencia como la imparcialidad de los jueces se asegura mediante la selección de las personas más capacitadas -en sentido integral, o sea ético, intelectual, de carácter, etc.- para el desempeño de la elevada función de juzgar" ${ }^{15}$.

El derecho al juez predeterminado resguarda al ciudadano "frente a las tentaciones que podría tener el Ejecutivo de ir creando tribunales por decreto para realizar objetivos particulares de dicho poder del Estado" 16 . Digamos que esa tentación la podrían tener los otros poderes del Estado. Hay que ser ingenuo para desconocer que la elección del tribunal puede determinar el resultado del proceso.

El Tribunal Constitucional español ha declarado que el interés directo del derecho al juez ordinario predeterminado por la ley ${ }^{17}$, es el resguardo de la garantía de independencia e imparcialidad de los jueces ${ }^{18}$.

La Constitución, cuando se refiere a la "perpetración del hecho" parece sugerir que se refiere a un delito $y$, por tanto, pudiésemos concluir

13 Sentencia Tribunal Constitucional de España 69/2001, 17 de marzo de 2001. Boletín Oficial del Estado núm. 83 de 6 de abril de 2001, pp. 145 a 155.

14 Romero (2009) 37.

15 Pacheco G., Máximo (1990) Teoría del Derecho. 4a edición. Santiago: Editorial Jurídica de Chile, p. 185.

Vivanco (2006) 315.

Sancionado con esta terminología en el artículo 24.2 de la Constitución española.

Sentencia Tribunal Constitucional de España 37/2013, 14 de febrero de 2013. Boletín Oficial del Estado num. 61 de 12 de marzo de 2013, pp. 145 a 155. 
que el derecho al juez predeterminado solo está vinculado al proceso penal. Sin embargo, los Tratados Internacionales en materia de derechos humanos contemplan este derecho como un componente del debido proceso, con especial énfasis en el ámbito del proceso penal, aunque considerando también otras áreas del derecho. Así, la Convención Americana sobre Derechos Humanos, en su artículo $8 \mathrm{~N}^{\circ} 1$, establece que "Toda persona tiene derecho a ser oida, con las debidas garantías y dentro de un plazo razonable, por un juez o tribunal competente, independiente e imparcial, establecido con anterioridad por la ley, en la sustanciación de cualquier acusación penal formulada contra ella, o para la determinación de sus derechos y obligaciones de orden civil, laboral, fiscal o de cualquier otro carácter".

En tanto componente del debido proceso o del proceso racional y justo (en la terminología constitucional chilena), no se puede sino concluir que el derecho al juez predeterminado es una exigencia en cualquier proceso judicial por cuanto, aun cuando la afectación de derechos en procesos distintos del penal pueda ser menor, aunque nunca irrelevante; igualmente existen en esos otros ámbitos los mismos riesgos que prevenir.

Es, por lo señalado, que resulta fundamental determinar la competencia de los tribunales y, en particular, el tribunal que conocerá de cada uno de los asuntos. En este sentido, la determinación del tribunal competente no es una cuestión azarosa o casual, sino que responde a criterios establecidos por la ley, aunque no siempre de un modo expreso o claro, de manera que es la doctrina la que en muchas ocasiones debe hacer los análisis necesarios para desentrañarlos.

No es admisible que el tribunal, conforme los razonamientos que preceden, quede indeterminado o, en otras palabras, no exista un criterio legal, esto es, con caracteres de objetividad y generalidad; conforme al cual distribuir la competencia de los tribunales. De tal manera, los factores de competencia deben ser tales que permitan determinar de modo exacto y preciso el tribunal competente para conocer de un conflicto o establecer las bases para que ese tribunal sea determinado.

La competencia del tribunal constituye un presupuesto procesal, vale decir, una condición de validez del proceso cuya infracción genera la privación de efectos jurídicos al proceso mismo. Determinar cuáles son los elementos de la competencia supone establecer el marco de actuación válida del tribunal en el proceso.

Analizaré a continuación los criterios de distribución de la jurisdicción en el ordenamiento jurídico nacional, también llamados elementos o factores de la competencia. 


\section{2) La Materia, Fuero, Cuantía y Territorio}

En Chile, la enseńanza tradicional nos indica que los factores para distribuir el ejercicio de la jurisdicción son cuatro: materia, fuero, cuantía y territorio ${ }^{19}$.

Esta tesis ha sido respaldada por la jurisprudencia de los tribunales. Así, la Corte Suprema ha declarado que "las reglas de competencia se orientan a determinar cuál será el tribunal competente para conocer de un asunto determinado, pudiendo reconocerse aquellas de carácter general, aplicables a toda clase de materia y tipo de tribunales -de radicación; del grado o jerarquía; de extensión; de prevención o inexcusabilidad y de ejecución- y las especiales, que dicen relación con la competencia de los tribunales que integran el Poder Judicial, pudiendo a su vez distinguirse entre estas, las relativas a la competencia absoluta, esto es, la cuantía, la materia y el fuero personal, y las de competencia relativa, que son aquellas que tienen por objeto determinar de entre tribunales de una misma jerarquía o categoría, cual de ellos será el competente para conocer de un asunto determinado" 20 .

19 Así lo plantean autores como Casarino Viterbo, Mario (1995): Manual de Derecho Procesal. Derecho Procesal Orgánico. T. I. Santiago: Editorial Jurídica de Chile; Colombo CampBell, Juan (2004): La Competencia. Santiago de Chile: Editorial Jurídica de Chile; Pereira Anabalón, Hugo (1993), Curso de Derecho Procesal, Tomo I, Derecho Procesal Orgánico. Santiago de Chile: Editorial Jurídica ConoSur (aunque este autor sostiene además que el grado es un factor de competencia como referiré más adelante); Lillo Hunzinker, Lenin (1998): "Curso de Derecho Procesal Civil orgánico de tribunales. s. 1.: Ediciones Jurídicas La Ley; Hermosilla Arriagada, Germán (2006): Derecho Procesal Orgánico. Santiago de Chile: Editorial Thomson Reuters Puntolex; Salas Astraín, Jaime (2006): Iniciación al nuevo Derecho Procesal chileno. Santiago de Chile: Editorial Alfakira; Díaz Uribe, Claudio (2006): Curso de Derecho Procesal Civil T. I. Santiago de Chile: Abeledo Perrot LegalPublishing Chile - Thomsom Reuters; Orellana Torres, Fernando (2010): Manual de Derecho Procesal, T. I. Santiago de Chile: Editorial Librotecnia; Chávez Chávez, Eric Andrés (2008): Derecho Procesal Orgánico y Funcional. Santiago de Chile: Editorial Jurídica Aremi; Oberg YÁNez, Héctor y Manso Villalón, Macarena (2008): Derecho Procesal Orgánico. Santiago de Chile: LexisNexis - LegalPublishing Chile; Correa Selame, Jorge Danilo (2012): Manual de Derecho Procesal, T. I. Santiago de Chile: Editorial Jurídica Aremi; Figueroa Yávar, Juan Agustín y Morgado SAN MarTín, Erika (2013): Jurisdicción, competencia y disposiciones comunes a todo procedimiento. Santiago de Chile: LegalPublishing Chile-Thomsom Reuters; Núñez Ojeda, Raúl y Pérez Ragone, Alvaro (2013): Manual de Derecho Procesal Civil. Parte General. Santiago de Chile: LegalPublishing-Thomsom Reuters; Romero Seguel, Alejandro (2009): Curso de Derecho Procesal Civil. Los presupuestos procesales relativos al órgano jurisdiccional. T. I. Santiago: Editorial Jurídica de Chile.

20 Sentencia Corte Suprema. 9 de diciembre de 2013. Rol: 9252-2012. Recurso de casación en la forma y en el fondo en causa "Adm. de Inv. y Sup. Unimarc S.A. con Empresa de Servicios Sanitarios del Bio Bio S.A., Interagro Comercio y Ganado S.A.” Con base en la misma doctrina se pueden citar las sentencias de la misma Corte de 17 de marzo de 2014. Rol 10766-2013. Recurso de casación en la forma y en el fondo en causa "Santander Asset Management con Comercial e Inversiones Atlantida S. A. y otro"; de 5 de marzo de 2014. ROL 5967-2013. Recurso de unificación de jurisprudencia en materia laboral "Andrade con Ministerio Publico"; y de 15 de octubre de 2013. ROL 2688-2012. Recurso de casación 
Para Chiovenda la materia y la cuantía son parte del criterio que denomina objetivo que se deriva "o del valor del pleito (competencia por valor), o de la naturaleza del pleito (competencia por materia)"21-22. Autores como Ramos Méndez ${ }^{23}$, Devis Echandía ${ }^{24}$ y Palacio $^{25}$, siguen esta misma denominación, agrupando así los factores materia y cuantía. Alvarado Velloso denomina competencia material a aquel criterio que se funda en la materia sobre la cual versa la pretensión; y competencia cuantitativa o en razón del valor a aquel que se funda en el valor pecuniario comprometido en el litigio ${ }^{26}$.

En verdad la doctrina utiliza indistintamente los conceptos de criterio, elemento o factor de competencia para referirse al mismo objeto; sin embargo, la denominación de criterio reiteradamente no aparece referida a un elemento o factor de competencia, sino a una clase de ellos; razón por la cual el criterio permite incluir dos o más de aquellos que la doctrina chilena califica como elementos o factores. Sin embargo, esta distinción no es explicitada; más aún, existen autores como Moreno que denomina criterio a los elementos o factores de competencia. Así, el mismo MoreNo explica que "la competencia objetiva determina, en razón del objeto del proceso propuesto por el actor en la demanda, cuál es el órgano que debe conocer de la primera instancia con exclusión de cualquier otro" 27. El objeto del proceso propuesto por el actor se puede definir tanto por la materia como por la cuantía, lo que lleva a los autores citados a estimar que el criterio objetivo agrupa los elementos materia y cuantía ${ }^{28}$. Moreno incluye además, dentro de la competencia objetiva tres 'criterios': el de la

en el fondo "Sociedad Agricola Vásquez Ltda. con Fisco de Chile". Disponibles en http:// suprema.poderjudicial.cl/SITSUPPORWEB/InicioAplicacion.do [fecha de visita 23 de diciembre de 2014].

21 Chiovenda, José (1922): Principios de Derecho Procesal Civil T. I. Traducción de José CaSÁIS y Santaló. Madrid: Editorial Reus, p. 600.

22 En rigor, el criterio objetivo reúne dos criterios de asignación de competencia, como son: la materia y la cuantía, de modo que más que un criterio, es una clase o categoría de criterios que se caracteriza porque son determinados por las características del conflicto: su naturaleza (materia) y su importancia (cuantía).

23 Ramos Méndez, Francisco (1980): Derecho Procesal Civil. Barcelona: Librería Bosch, p. 153.

24 Devis Echandía, Hernando (2012): Teoría General del Proceso. Bogotá: Editorial Temis, p. 117.

25 Palacio, Lino Enrique (2003): Manual de Derecho Procesal Civil. Buenos Aires: Editorial LexisNexis, p. 193.

26 Alvarado Velloso, Adolfo (2011): Lecciones de Derecho Procesal Civil. Santiago de Chile: Thomson Reuters Puntolex, p. 137.

27 Moreno Catena, Víctor (2003): Derecho Procesal Civil. Parte General. Editorial Colex, p. 54.

28 En el mismo sentido Gil SuÁrez, Luis (2001): "Jurisdicción y competencia”, Revista del Ministerio de Trabajo y Asuntos Sociales. $\mathrm{N}^{\circ} 28$, pp. 17 y ss. 
persona del demandado (que equivale al de la persona o fuero en la doctrina chilena), el de la materia y el de la cuantía ${ }^{29}$.

El citado Chiovenda reconoce, como el resto de la doctrina, la existencia de una competencia territorial que se conecta "a la circunscripción territorial, a la atribuida a la actividad de cada órgano jurisdiccional” 30 .

Respecto del fuero, el maestro de Bologna sostiene que "La cualidad de las personas litigantes ha tenido en otro tiempo gran importancia para la formación de jurisdicciones especiales (privilegiadas); pero hoy por sí sola no influye en la competencia del juez, salvo en casos excepcionalísimos (así en los tribunales privilegiados de la Administración pública, admitidos por nuestras leyes solo para la Colonia Erítrea; así en la competencia de los cónsules, limitada por la cualidad de ciudadanos de los litigantes o, por lo menos, del demandado; en la competencia de los tribunales mixtos antes recordados; así en la jurisdicción penal del Senado sobre los senadores; así en la jurisdicción penal militar"31. Devis ECHANDía cuenta como uno de los factores de la competencia el subjeti$v o^{32}$ que "mira a la calidad de las personas que forman las partes del proceso: nación, departamentos, municipios, área metropolitana, regiones, o al cargo público que desempeña el sindicado, en lo penal; en razón de ella se adscriben los procesos civiles en los cuales es parte alguna de esas entidades, a los jueces del circuito cualquiera que sea su valor, y los procesos penales contra ciertos funcionarios; a los tribunales o la sala penal de la Corte Suprema" 33 . Palacio sostiene que entre los criterios de distribución de competencia "cabe añadir el criterio personal (competencia ratione personae), emergente de la calidad o condición de las partes (Nación, embajadores, cónsules, etc.), o de la vecindad o nacionalidad de estas"34. AlvaRADO VELloso se refiere a este criterio como el de competencia personal, que se funda en las personas que se hallan en litigio ${ }^{35}$.

Desde luego que los factores de competencia tienen particularidades locales, toda vez que dependen del tratamiento que se haga en la ley de cada Estado, a la forma en que se distribuirá la competencia entre los distintos tribunales que se creen para conocer de los asuntos que correspon-

\footnotetext{
29 Moreno (2003) 54.

Alvarado (2011) 137.

Chiovenda (1922) 600.

El concepto de competencia subjetiva es utilizado en oposición a objetiva, de manera que la competencia objetiva se refiere al órgano jurisdiccional con abstracción de quien sea su titular en ese momento. La competencia subjetiva alude a su titular, a la persona o personas físicas encargadas del desenvolvimiento, del desempeño de las funciones del órgano, que se refiere a las pautas que tienden a mantener aséptico el campo del juzgamiento, particularmente la independencia e imparcialidad. En este sentido Gómez Lara, Cipriano (2004): Teoría General del Proceso. Ciudad de México: Editorial Oxford, p. 146; y Alvarado (2011) 138.

33 Devis (1964) 117.

34 Palacio (2003) 193.

35 Alvarado (2011) 137.
} 
den a la jurisdicción. Por ello, es que resulta comprensible que el factor fuero o persona no aparezca mencionado por algunos autores como ocurre con el caso de la literatura procesal mexicana ${ }^{36}$.

Materia, fuero o persona, cuantía o territorio son factores que, unánimemente o no, son mencionados en los estudios de derecho procesal comparado como aquellos que sirven para distribuir la jurisdicción entre los distintos tribunales. Pero, ¿son los únicos factores que sirven para tal propósito? Estos factores, ¿pueden por sí solos dar cuenta de todas las situaciones que se presentan en nuestras normas procesales? La respuesta es no, como pretendo demostrar en las líneas que siguen.

\section{3) LOS OTROS ELEMENTOS DE LA COMPETENCIA}

\section{1) EL GRADO}

Los cuatro factores tradicionales en Chile no permiten explicar cómo se distribuye la competencia entre los tribunales inferiores y superiores. Es habitual que ambos tipos de tribunales conozcan de causas referidas a la misma materia, fuero, cuantía y territorio. Es más, conocen de los mismos procesos. Los cuatro factores no permiten discriminar cuál es el tribunal competente para conocer del asunto.

En la doctrina comparada se menciona por diversos autores el criterio funcional, que se deriva "de la naturaleza especial y de las exigencias también especiales de las funciones que el magistrado está llamado a ejercer en un solo proceso, cuyas funciones pueden estar distribuidas entre diversos órganos; así hay jueces de primero y segundo grado (competencia por grado), jueces de conocimiento, jueces de ejecución; y también pueden ser confiadas al juez de un cierto territorio precisamente en vista de la exigencia de las funciones, dando lugar a una competencia en la que el elemento funcional concurre con el territorial ${ }^{37 "}$. Otros autores mencionan directamente como criterio de competencia el grado o instancia, entendido como cada cognición del litigio por un juzgador.

\footnotetext{
36 La doctrina mexicana reconoce cuatro criterios o factores fundamentales para determinar la competencia, que corresponden a los que la legislación expresamente establece como tales. Así el artículo 144 del Código de Procedimientos Civiles para el Distrito Federal dispone "La competencia de los tribunales se determinará por la materia, la cuantía, el grado y el territorio". Además de estos criterios la doctrina describe otros factores que denomina complementarios o secundarios. Al efecto se pueden ver autores tales como Armienta Calderón, Gonzalo (2003): Teoria general del proceso. Ciudad de México: Editorial Porrúa, pp. 65 y ss.;

Gómez (2004) pp. 145 y ss.; y Ovalle Favela, José (2010): Teoría General del Proceso. Ciudad de México: Editorial Oxford, pp. 136 y ss. Chiovenda (1922) 600.
} 
Desde luego el grado comprende, en este análisis, no solo lo que conocemos como instancia propiamente tal, que en nuestro ordenamiento solo pueden ser dos, vinculada estrictamente al recurso de apelación; sino también todo conocimiento del proceso que realiza un tribunal de distinta jerarquía activado por la interposición de un recurso.

Pereira Anabalón advertía entre nosotros que "Algunos autores también consideran $-y$ con razón- que es elemento de la competencia el grado o instancia en que los tribunales conocen y resuelven los asuntos judiciales, de modo que existe un primer grado o primera instancia $y$, consecuentemente, competencia de primera instancia, como asimismo un segundo grado o instancia que daría al respectivo tribunal competencia de segunda instancia" ${ }^{38}$. Luego, sin embargo, no desarrolla mayormente el punto salvo para indicar que "En el derecho vigente este elemento de la competencia es recogido por el artículo 188 del Código Orgánico de Tribunales"39-40.

Considerar que el grado es el equivalente a instancia, para estos efectos al menos, deja sin explicación la forma en que se ha distribuido la competencia para permitir que algunos tribunales conozcan de algunos procesos con motivo de recursos que no generan una nueva instancia de conocimiento como la casación, la nulidad, la queja, etc. Por esta razón, el concepto de grado es asimilado por la doctrina a la idea de jerarquía más que a la de instancia.

Resulta curiosa la omisión que se ha producido en la doctrina nacional sobre el grado como factor de competencia ya que se encuentra presente en nuestras normas procesales ${ }^{41}$. No es explicación suficiente

38 Pereira Anabalón, Hugo (1993), Curso de Derecho Procesal, Tomo I, Derecho Procesal Orgánico. Santiago de Chile: Editorial Jurídica ConoSur, p. 162.

39 Pereira (1993) 163.

$40 \quad$ El artículo 188 del Código Orgánico de Tribunales señala: "La competencia de que se halla revestido un tribunal puede ser o para fallar un asunto en una sola instancia, de modo que la sentencia sea inapelable; o para fallarlo en primera instancia, de manera que la sentencia quede sujeta al recurso de apelación".

41 Los artículos 45 y 63, que transcribo a continuación, establecen la competencia de los juzgados de letras y de la Cortes de Apelaciones sobre la base, entre otros, del criterio del grado:

Artículo 45. Los jueces de letras conocerán:

1. ${ }^{\circ}$ En unica instancia:

a) De las causas civiles cuya cuantía no exceda de 10 Unidades Tributarias Mensuales;

b) De las causas de comercio cuya cuantía no exceda de 10 Unidades Tributarias Mensuales, y

2. ${ }^{\circ}$ En primera instancia:

a) De las causas civiles y de comercio cuya cuantía exceda de 10 Unidades Tributarias Mensuales;

b) De las causas de minas, cualquiera que sea su cuantía. Se entiende por causas de minas, aquellas en que se ventilan derechos regidos especialmente por el Código de Minería;

c) De los actos judiciales no contenciosos, cualquiera que sea su cuantía, salvo lo dispuesto en el artículo 494 del Código Civil;

d) Derogada.

e) Derogada. 
para esta omisión la circunstancia de que el grado tenga un tratamiento tan sencillo en nuestro ordenamiento, a partir de la aplicación de la regla general de competencia del grado que se expresa en el artículo $110 \mathrm{del}$ COT, del modo siguiente: "Una vez fijada con arreglo a la ley la competencia de un juez inferior para conocer en primera instancia de un determinado asunto, queda igualmente fijada la del tribunal superior que debe conocer del mismo asunto en segunda instancia”.

De tal manera, los factores de competencia no son solo los cuatro tradicionales que la doctrina nacional enseña, sino que a la materia, fuero, cuantía y territorio, debemos agregar el grado.

f) Derogada.

g) De las causas civiles y de comercio cuya cuantía sea inferior a las señaladas en las letras a) $y$ b) del No. 1 de este artículo, en que sean parte o tengan interés los Comandantes en Jefe del Ejército, de la Armada y de la Fuerza Aérea, el General Director de Carabineros, los Ministros de la Corte Suprema o de alguna Corte de Apelaciones, los Fiscales de estos tribunales, los jueces letrados, los párrocos y vicepárrocos, los cónsules generales, cónsules o vicecónsules de las naciones extranjeras reconocidas por el Presidente de la República, las corporaciones y fundaciones de derecho público o de los establecimientos públicos de beneficencia, y

b) De las causas del trabajo y de familia cuyo conocimiento no corresponda a los Juzgados de Letras del Trabajo, de Cobranza Laboral y Previsional o de Familia, respectivamente.

3. ${ }^{\circ}$ Derogada.

$4 .{ }^{\circ}$ De los demás asuntos que otras leyes les encomienden.

Artículo 63. Las Cortes de Apelaciones conocerán:

1. ${ }^{\circ}$ En única instancia:

a) De los recursos de casación en la forma que se interpongan en contra de las sentencias dictadas por los jueces de letras de su territorio jurisdiccional o por uno de sus ministros, y de las sentencias definitivas de primera instancia dictadas por jueces árbitros;

b) De los recursos de nulidad interpuestos en contra de las sentencias definitivas dictadas por un tribunal con competencia en lo criminal, cuando corresponda de acuerdo a la ley procesal;

c) De los recursos de queja que se deduzcan en contra de jueces de letras, jueces de policía local, jueces árbitros y órganos que ejerzan jurisdicción, dentro de su territorio jurisdiccional;

d) De la extradición activa; $y$

e) De las solicitudes que se formulen, de conformidad a la ley procesal, para declarar si concurren las circunstancias que habilitan a la autoridad requerida para negarse a proporcionar determinada información, siempre que la razón invocada no fuere que la publicidad pudiere afectar la seguridad nacional.

$2{ }^{\circ}$ En primera instancia:

a) De los desafueros de las personas a quienes les fueren aplicables los incisos segundo, tercero y cuarto del artículo 58 de la Constitución Política de la República;

b) De los recursos de amparo y de protección, y

c) De los procesos por amovilidad que se entablen en contra de los jueces de letras, y

d) De las querellas de capítulos.

3..$^{\circ}$ En segunda instancia:

a) De las causas civiles, de familia y del trabajo y de los actos no contenciosos de que hayan conocido en primera los jueces de letras de su territorio jurisdiccional o uno de sus ministros, y

b) De las apelaciones interpuestas en contra de las resoluciones dictadas por un juez de garantía.

4. ${ }^{\circ}$ De las consultas de las sentencias civiles dictadas por los jueces de letras.

5. ${ }^{\circ}$ De los demás asuntos que otras leyes les encomienden. 


\section{2) EL TURNO}

Sin embargo, los cinco factores señalados son insuficientes para explicar la forma en que se distribuye la jurisdicción entre los tribunales nacionales.

Alsina expone que "las circunstancias pueden exigir una nueva división del trabajo, en virtud de la cual, a jueces de la misma competencia se les fija determinados días para la recepción de las causas nuevas, a fin de hacer una distribución equitativa del trabajo entre los mismos. Es así como un juez, no obstante ser competente para entender en una causa civil, debe negarse a intervenir si es iniciada fuera del turno que le ha sido asignado" 42 .

Gómez Lara define el turno como "un sistema de distribución de los asuntos nuevos entre diversos órganos jurisdiccionales, ya sea en razón del orden de presentación de dichos asuntos o en razón de la fecha en la cual estos se inician". Luego el autor agrega "Si el turno se establece no por fechas, sino por orden de llegada de los asuntos, es claro que debe organizarse una oficialía de partes única para todos los juzgados, la que distribuirá los asuntos nuevos entre los juzgados en función del orden de presentación" ${ }^{33}$. En el mismo sentido de dar al turno un significado amplio, Ovalle Favela señala que este "se puede llevar a cabo por períodos (horas, días, semanas, etc.), por orden de ingreso, por programas automatizados, etcétera" ${ }^{44}$.

El turno, como sistema de distribución por fechas, está reglado en Chile en los artículos 175 y 179 del Código Orgánico de Tribunales. La primera norma se aplica en las comunas o agrupaciones de comunas que no fueren asiento de Corte, en donde hubiere más de un juez de letras, el turno se ejerce por semanas; comienza a desempeñarlo el juez más antiguo y seguirán desempeñándolo todos los demás por el orden de su antigüedad. La segunda norma se aplica a la competencia delegada y a los asuntos judiciales no contenciosos.

El turno, como sistema de distribución por orden de llegada, se contempla en el artículo 176 del Código Orgánico de Tribunales. Rige este sistema en los lugares de asiento de Corte en que hubiere más de un juez de letras en lo civil. Exige que toda demanda o gestión judicial que se iniciare y que deba conocer alguno de dichos jueces deberá presentarse a la secretaría de la Corte, a fin de que se designe el juez a quien corresponda su conocimiento. La designación se hace por el presidente del tribunal,

\footnotetext{
42 Alsina, Hugo (1957): Tratado teórico práctico de Derecho Procesal Civil y Comercial, T. II. Organización judicial, jurisdicción y competencia. Buenos Aires: Ediar, p. 511.

43 Gómez Lara, Cipriano (2004): Teoría General del Proceso. Ciudad de México: Editorial Oxford, pp. 150-151.

44 Ovalle (2010) 143
} 
sin que la ley establezca los criterios conforme a los cuales se realiza, pero en la práctica el sistema aplicado era el orden de llegada ya que asegura la equidad y objetividad en la distribución del trabajo. Hoy este sistema se realiza mediante sistemas informáticos que además de equidad y objetividad, aseguran que la distribución sea aleatoria.

Alvarado Velloso explica que "cuando son varios los jueces que ostentan una idéntica suma de competencias (territorial, material, funcional, personal y cuantitativa), se hace necesario asegurar entre ellos un equitativo reparto de tareas, con lo cual se crea el turno judicial que, sin ser pauta atributiva de competencia puede equipararse a ellas a los fines de esta explicación" ${ }^{45}$.

Gómez Lara cree que el turno es un "fenómeno de afinación de la competencia" más que un criterio de determinación de la misma. Ovalle FaVELa cree que no es un criterio para determinar la competencia, "sino solo un orden interno de distribución de los asuntos que ingresan, que no afecta, en modo alguno, la competencia de los órganos jurisdiccionales" 46 .

Gómez Colomer estima que una vez que se ha determinado la competencia conforme a los tres criterios de atribución conocidos (competencia objetiva, funcional y territorial) se hace necesario otras disposiciones para fijar exactamente, dentro del lugar, qué juzgado o tribunal conocerá definitivamente la pretensión, lo que se denomina reparto de negocios o asuntos. Sostiene que el reparto no significa en absoluto la aplicación de una norma de competencia. "Estamos en cambio ante normas que, fundándose en el principio de la necesaria división del trabajo, tiene un carácter gubernativo" 47 .

Pereira Anabalón tampoco cree que el turno sea una regla de competencia. Al efecto señala que "por su alojamiento en el mencionado Título (VII del Código Orgánico de Tribunales) aparecen en el texto como reglas de competencia. Sin embargo, la redacción del epígrafe indica que la división del trabajo judicial que regula se realiza entre jueces que tienen "igual competencia", lo que indica claramente que entre ellos no existen diferencias en tema de competencia, lo que a su vez permite razonar en el sentido que tales normas no son reglas de competencia, sino de otro rango, especie o naturaleza" 48 .

El mismo autor cita una sentencia de la Corte Suprema que estableció que "en los departamentos (hoy comunas) donde hay más de un juez de letras, todos tienen la misma jurisdicción (competencia) para conocer de los asuntos que se promuevan dentro de los límites del departamen-

Alvarado (2011) 138.

Ovalle (2010) 136.

Gómez Colomer, Juan Luis (2003): Derecho Jurisdiccional I. Parte General. T. I. Valencia:

Editorial Tirant lo Blanch, p. 232.

48 Pereira (1993) 202. 
to (comuna) en que se desempeñan y las reglas destinadas a repartir o distribuir entre ellos los juicios o gestiones de que deben conocer solo se refieren a la más expedita administración de justicia, pero no a la facultad que poseen de conocer y juzgar" (considerando $\left.10^{\circ}\right)$ "49. Agrega el autor que "Si las reglas del turno y la distribución de causas miran a la equitativa distribución del trabajo judicial y no a la competencia de los tribunales, carecen de carácter jurisdiccional y son, por su índole, administrativas. Pero, atendida su finalidad, tienen carácter público, lo que permite al tribunal excusarse de oficio de proveer, si no se han observado sus disposiciones" 50 .

En mi opinión, resulta muy extraña la clasificación entre reglas de competencia y reglas de distribución de causas que realizan numerosos autores. Desde el punto de vista del justiciable, son reglas de competencia las que determinan el tribunal que conocerá del asunto y, por lo tanto, le brindan la posibilidad de reclamar la intervención de ese y no otro tribunal. La expresión "reglas de distribución de causas" o "reglas de reparto de negocios" observa el mismo fenómeno, pero desde la óptica del sistema de justicia, al que le interesa, no necesariamente resguardar el derecho del justiciable, sino obtener una distribución equitativa y eficiente del trabajo jurisdiccional entre los órganos que forman parte del sistema. Negar la categoría de reglas de competencia a estas reglas, solo pretenden evitar que las partes puedan reclamar de dicho vicio, generando espacios de disponibilidad de las competencias, con el riesgo de asignación discrecional de causas, lo que vulnera el derecho al juez predeterminado.

Es imposible reconocer al tribunal la facultad de "excusarse de oficio de proveer" si no se han observado las disposiciones del turno -como señala Pereira Anabalón-; si es que no se reconoce a este como un criterio de competencia. Si el turno no es un criterio de competencia, al excusarse el juez de conocer de la causa vulnera el principio de inexcusabilidad que en el artículo 10 del Código Orgánico de Tribunales dispone que "Reclamada su intervención en forma legal y en negocios de su competencia, no podrán excusarse de ejercer su autoridad ni aún por falta de ley que resuelva la contienda sometida a su decisión"; y que en el artículo 112 del mismo Código señala en forma igualmente prohibitiva "siempre que según la ley fueren competentes para conocer de un mismo asunto dos o más tribunales, ninguno de ellos podrá excusarse del conocimiento bajo el pretexto de haber otros tribunales que puedan conocer del mismo asunto".

Concuerdo en que el tribunal que no se encuentra de turno puede excusarse del conocimiento de una causa; pero ello se debe a que el turno

49 Pereira (1993) 202. El caso es Contreras con Gouet (1964).

50 Pereira (1993) 202. 
es una regla de competencia, el que sí es un motivo legal suficiente para excusarse de ejercer su jurisdicción.

Si se reconoce al tribunal la facultad de excusarse de conocer de una causa por habérsele presentado fuera de su turno, debe igualmente reconocerse a la parte afectada la posibilidad de reclamar de ese vicio. Esta es la única posibilidad de evitar la disponibilidad de las competencias y la asignación discrecional de las causas.

El turno es un criterio de distribución del ejercicio de la jurisdicción en el ordenamiento jurídico chileno que se encuentra establecido por la ley y permite determinar el tribunal competente para conocer de un asunto. En mi opinión, debemos en Chile sumar un sexto elemento de la competencia a los ya mencionados anteriormente.

El turno como criterio de competencia ha sido defendido en Chile por Luco quien señala al efecto cuatro motivos para esta conclusión: en primer lugar, "el turno y la distribución de causas surgen, como toda norma de competencia, de la existencia de dos o más tribunales potencialmente competentes para conocer de un asunto"; en segundo lugar, "el turno y la distribución de causas son dos o más de los distintos criterios para ir entregando asuntos a uno u otro tribunal, tan válidos y eficaces como la materia, la cuantía, el territorio, etc."; en tercer lugar, "el objeto del turno y la distribución de causas es el mismo que el de los demás factores de la competencia: precisar un tribunal competente para conocer de un asunto determinado"; y, en cuarto lugar, "negar el carácter de normas de competencia al turno y la distribución de causas implica desconocer que la determinación del tribunal competente es una labor que se efectúa en distintos grados" 51 .

Es necesario recordar en este punto que entre las exigencias del derecho al juez predeterminado, que he enunciado en la primera parte de este trabajo, se encuentra aquella que indica que no puede haber concurrencia de la competencia, esto es, no pueden haber dos o más tribunales igualmente competentes. El turno, como elemento de competencia, resuelve el problema de la aparente concurrencia de la competencia entre dos o más tribunales que se produce con la sola aplicación de los elementos de competencia anteriores.

\section{3) LA ATRACCIÓN}

Algunos autores señalan como elemento de la competencia la atracción que "Consiste en la acumulación que debe realizarse de los juicios singulares que se sigan contra una persona, al juicio universal que se promueva en caso de que dicha persona fallezca (juicio sucesorio), o sea

51 Luco, Nicolás (2002): "Naturaleza de las reglas del turno y distribución de causas y sanción a su infracción”, Revista de Derecho y Jurisprudencia, Tomo XCIX, No 2, pp. 18-19. 
declarada en estado de insolvencia (juicio de concurso mercantil, si es comerciante, o de concurso civil, si no lo es)" 52 .

Esta especie de atracción se encuentra contemplada en el artículo 142 de la Ley 20.720 que "Sustituye el régimen concursal vigente por una ley de reorganización y liquidación de empresas y personas, y perfecciona el rol de la Superintendencia del ramo" que dispone que "Todos los juicios civiles pendientes contra el Deudor ante otros tribunales se acumularán al Procedimiento Concursal de Liquidación. Los que se inicien con posterioridad a la notificación de la Resolución de Liquidación se promoverán ante el tribunal que esté conociendo del Procedimiento Concursal de Liquidación".

La atracción determina en muchos casos la modificación de la competencia que tiene un tribunal respecto del proceso singular, el que deja de ser competente para pasar a serlo el tribunal que conoce del proceso de liquidación. En Chile, esta situación es explicada por la doctrina nacional $^{53}$ como una excepción a la regla de radicación del artículo 109 del Código Orgánico de Tribunales.

El fenómeno de la atracción no puede ser explicado por ninguno de los anteriores factores de competencia, de modo que ello lo transforma en un elemento propio.

\section{4) LA CONEXIDAD}

También se menciona por autores extranjeros el factor de la conexidad o conexión como factor de competencia. "Este elemento se presenta cuando dos o más procesos comparten elementos en común, ya sea la causa petendi o el objeto -en cuyo caso se le conoce como conexidad objetiva-, o bien, litigan las mismas partes -conexidad subjetiva-" 54 .

El efecto de la conexidad es la acumulación de los procesos que "consiste en la reunión en un solo proceso de todos los juicios que se estaban tramitando separadamente, cuando el fallo de uno de ellos deba producir cosa juzgada en el o los otros; o cuando se cumplan otros requisitos que los Códigos de Procedimiento Civil o Penal se encargan de establecer" ${ }^{55}$.

En materia procesal civil la conexidad está tratada en Chile en los artículos 92 y siguientes del Código de Procedimiento Civil y tiene lugar en los siguientes casos:

$1^{\circ}$ Cuando la acción o acciones entabladas en un juicio sean iguales a las que se hayan deducido en otro, o cuando unas y otras emanen directa e inmediatamente de unos mismos hechos;

\footnotetext{
52 Ovalle (2010) 141.

53 A modo meramente ejemplar; ver Colombo (2004) 154; Orellana (2010) 251; Oberg y Manso (2008) 52.

54 Armienta (2003) 69.

55 Cоlомво (2004) 154.
} 
$2^{\circ}$ Cuando las personas y el objeto o materia de los juicios sean idénticos, aunque las acciones sean distintas; $y$

$3^{\circ}$ En general, siempre que la sentencia que haya de pronunciarse en un juicio deba producir la excepción de cosa juzgada en otro.

El artículo 96 del referido Código determina el Tribunal competente según las siguientes fórmulas:

$1^{\circ}$ Si los juicios están pendientes ante tribunales de igual jerarquía, el más moderno se acumulará al más antiguo;

$2^{\circ} \mathrm{Si}$ los juicios están pendientes ante tribunales de distinta jerarquía, la acumulación se hará sobre aquel que esté sometido al tribunal superior.

El conocimiento de la reconvención o demanda reconvencional le corresponde conocerla al tribunal que conoce de la demanda principal conforme al criterio de conexidad o conexión.

En materia penal, la conexidad tiene lugar en aquellos casos en que, en ejercicio de las facultades que la ley procesal penal confiere al Ministerio Público, este decidiere investigar en forma conjunta hechos constitutivos de delito, en los cuales correspondiere intervenir a más de un juez de garantía. En estos casos el conocimiento del asunto le corresponde al juez de garantía del lugar de comisión del primero de los hechos investigados (artículo 159 del Código Orgánico de Tribunales).

Al igual que en el caso anterior, la doctrina nacional ${ }^{56}$ trata la conexidad (sin esta denominación), como una excepción a la regla de radicación. Así, una vez que está radicada la competencia de un tribunal, al reunirse los diversos procesos en uno, puede alterar la radicación de la causa en los casos en que los procesos fueren conocidos por tribunales distintos, uno de los cuales dejará de conocer del asunto.

Para Chiovenda la conexión no es por sí misma un criterio de competencia, opinión en la que es seguido por Devis Echandía, pero ninguno proporciona razones para esta afirmación.

La misma razón que he explicado a propósito del análisis del turno es aplicable a la conexidad. Solamente la circunstancia de que se trata de un criterio de competencia es lo que permite que un tribunal se excuse de conocer un asunto y lo envíe a otro tribunal para que continúe su conocimiento, acumulada a otra causa; y la misma razón puede permitir que un tribunal reclame de otro el conocimiento de una causa de que este último conoce. Se trata de evitar una interpretación que pueda dar la posibilidad de disponer discrecionalmente de las competencias.

\section{5) LA ELECCIÓN}

Armienta señala como criterio de competencia la elección que "se genera cuando las partes consienten en la elección de un tribunal diverso

56 A modo meramente ejemplar; ver Colombo (2004) 155; Orellana (2010) 251. 
al señalado por la ley. Tal es el caso de la cláusula de competencia en los contratos, en la cual se contiene el pactum de foro prorrogando, mediante el cual se pacta una renuncia voluntaria a la competencia por razón del territorio" 57 .

La prórroga de la competencia es un acto por el cual las partes convienen expresa o tácitamente en someter el conocimiento de un asunto a un tribunal relativamente incompetente en los casos en que la ley lo permite.

La prórroga de la competencia está reglada en el artículo 181 del Código Orgánico de Tribunales que expresa que "Un tribunal que no es naturalmente competente para conocer de un determinado asunto, puede llegar a serlo si para ello las partes, expresa o tácitamente, convienen en prorrogarle la competencia para este negocio".

En mi opinión, tiene sentido afirmar que la elección o autonomía de la voluntad es un factor de la competencia cuando expresamente la ley permite que las partes modifiquen la competencia natural del tribunal, superponiendo esa voluntad por sobre la voluntad de la ley, lo que ocurre obviamente solo en los casos en que la ley lo permite.

Ya sea expresa o tácita, la prórroga de la competencia es un acto jurídico bilateral. Sin embargo, existe en la ley un número no menor de casos en que se dispone que la elección del tribunal competente le corresponde a una de las partes, particularmente al actor, lo que transforma al acto jurídico en unilateral, en tanto basta la manifestación de voluntad de una sola de las partes. Los casos en que es posible advertir elección unilateral son los siguientes:

- Caso del demandado que tiene varios domicilios: podrá el demandante entablar su demanda ante el juez de cualquiera de ellos (artículo 140 del Código Orgánico de Tribunales).

- Caso en que existan dos o más demandados con domicilios en distintos lugares: puede el demandante entablar su demanda ante el juez de cualquier lugar donde esté domiciliado uno de los demandados, y en tal caso quedarán los demás sujetos a la jurisdicción del mismo juez (artículo 141 del Código Orgánico de Tribunales).

- Caso en que la pretensión entablada fuere inmueble, será competente, a elección del demandante: el juez del lugar donde se contrajo la obligación; o el del lugar donde se encontrare la especie reclamada.

- Caso en que el inmueble o inmuebles que son objeto de la pretensión estuvieren situados en distintos territorios jurisdiccionales, será competente cualquiera de los jueces en cuya comuna o agrupación de comunas estuvieren situados (artículo 135 del Código Orgánico de Tribunales).

- En los juicios posesorios es competente para conocer de los interdictos posesorios el juez de letras del territorio jurisdiccional en que estuvieren situados los bienes a que se refieren. Si ellos, por su situa-

57 Armienta (2003) 71. 
ción, pertenecieren a varios territorios jurisdiccionales, será competente el juez de cualquiera de estos. (artículo 143 del Código Orgánico de Tribunales).

En los juicios de distribución de aguas es competente el de la comuna o agrupación de comunas en que se encuentra el predio del demandado. Si el predio estuviere ubicado en comunas o agrupaciones de comunas cuyo territorio correspondiere a distintos juzgados, será competente el de cualquiera de ellas (artículo 144 del Código Orgánico de Tribunales).

La elección es un criterio de competencia que permite precisar el tribunal competente.

Se podría afirmar que cuando la ley otorga la posibilidad de elección unilateral en verdad no está definiendo un criterio de competencia. Sin embargo, no es lo mismo definir la elección como criterio que no decir nada. Cuando se opta por el criterio de elección, entregando a ambas partes la posibilidad de modificar un criterio legal de competencia o a una de ellos de optar entre alternativas de tribunal competente, la ley impide que sea la autoridad la que elija el tribunal, lo que garantiza la indisponibilidad de la competencia.

$\mathrm{Al}$ entregar a una de las partes la decisión del tribunal competente entre alternativas diversas se establece un método cierto de definición del tribunal.

Claramente, los casos en que se aplica el criterio de elección son aquellos en que no hay razones de interés público que hagan necesario optar entre una u otra alternativa, de modo que a la luz de tales intereses la decisión que se adopte resulta irrelevante, aunque no lo es desde la perspectiva de definir la competencia del tribunal y, consecuentemente, del derecho al juez predeterminado.

\section{6) EL AZAR}

Los casos que se resuelven conforme al criterio de elección no son los únicos en los que la ley se encuentra ante tribunales alternativos entre los cuales no se puede discriminar sobre la base del interés público, de modo que el tribunal competente, dentro de esas alternativas, resulta solo relevante desde la perspectiva de la necesidad de predeterminar al juez que conocerá del asunto.

Es lo que ocurre en Chile en las Cortes de Apelaciones que constan de más de una sala, cada una de ellas habilitada para resolver los mismos casos. Cada sala de las Cortes de Apelaciones constituye un tribunal distinto. El artículo 66 del Código Orgánico de Tribunales dispone que "El conocimiento de todos los asuntos entregados a la competencia de las Cortes de Apelaciones pertenecerá a las salas en que estén divididas, a menos que la ley disponga expresamente que deban conocer de ellos en pleno." Luego agrega: "Cada sala representa a la Corte en los asuntos de 
que conoce". De este modo, cuando una sala de tal o cual Corte de Apelaciones resuelve un asunto, con propiedad se puede decir (y se dice) que es tal o cual Corte la que lo ha resuelto.

La ley pudo haber optado en estos casos por alguno de los criterios anteriores, particularmente por el turno, que puede resultar aplicable. Sin embargo, ha ideado una fórmula distinta que se explica en el artículo 69 del citado Código. De este modo, le asigna al Presidente de la respectiva Corte la tarea de formar el último día hábil de cada semana una tabla de los asuntos que verá el tribunal en la semana siguiente. En las Cortes que constan de más de una sala se han de formar tantas tablas cuantas sea el número de salas y se distribuirán entre ellas por sorteo. Sortear es, según el diccionario de la Real Academia de la Lengua, "someter a alguien o algo al resultado de los medios fortuitos o casuales que se emplean para fiar a la suerte una resolución”.

La ventaja de optar por el azar consiste en que la decisión no queda entregada discrecionalmente a ninguna persona $\mathrm{u}$ órgano, lo que asegura la indisponibilidad de la competencia.

La ley no describe particularmente el sorteo, salvo que debe ser en audiencia pública, lo que tiene por objeto dar transparencia al acto.

Luco sostiene que "las normas de distribución de causas entre las distintas secciones o salas de un mismo tribunal no son normas de competencia, porque no tienen por objeto establecer el tribunal competente sino que la sala precisa de ese tribunal competente que, en su representación -como dice el artículo 66 citado-conocerá del asunto. Tan claro es que no se trata de normas de competencia que si, por ejemplo, la segunda sala de la Corte Suprema -sala penal- conociera y resolviera, por error, de una materia civil, no podríamos decir que el fallo fue dictado por un tribunal incompetente en razón de la materia. La materia, en ese caso, solo determina la distribución del trabajo al interior del tribunal competente, pero no el tribunal competente" 58 .

La posición de Luco parte de un supuesto que no comparto que es el de estimar que el tribunal es la Corte Suprema o de Apelaciones respectiva y no la sala específica. La representación a que se refiere el artículo 66 ya citado, es una mera ficción legal, ya que sabemos que no es la "Corte" la que resuelve el asunto sino una sala específica que, en el marco del proceso, constituye el tercero imparcial que decide. La "Corte" es solo una estructura organizativa en la que se contienen diversos tribunales: cada una de las salas en las que se organiza y, en algunos casos, el pleno mismo. Si cada sala constituye un tribunal específico y distinto de la estructura que la cobija, el conocimiento del asunto por una sala (tribunal) distinta de aquella que determinan las reglas lo transforma en un tribunal competente. 
Las mismas razones que Luco ha dado, que ya reproduje, para sostener que el turno y la distribución de causas son normas de competencia son perfectamente aplicables al azar.

\section{7) EL TIEMPO O ÉPOCA EN QUE OCURREN LOS HECHOS}

Existen aún distintas situaciones en las que se advierte que los criterios analizados hasta ahora son insuficientes para resolver cuál es el tribunal competente.

Con motivo de la reforma al proceso penal iniciada en el año 2000 en Chile han funcionado coetáneamente para conocer de asuntos penales tres tribunales: los juzgados de garantía, los tribunales de juicio oral en lo penal y los juzgados del crimen o sus sucesores: los juzgados de letras; que distribuyen su competencia según si el asunto se somete a las reglas del antiguo o actual proceso penal, normados en el Código de Procedimiento Penal o Código Procesal Penal, respectivamente.

Para hacer esa distinción, la materia, el grado, el fuero, la cuantía, el turno, la atracción y la conexidad resultan irrelevantes, de modo que se hace necesario descifrar el factor que resulta necesario utilizar para lograr determinar el tribunal competente. En efecto, entre los tribunales que conocen del antiguo proceso y del actual no hay diferencias en cuanto a la materia y a la cuantía y los demás factores no permiten discriminar entre unos y otros.

Las normas que reglan la entrada en vigencia del nuevo proceso penal son los artículos 483 y 484 del Código Procesal Penal y el artículo $4^{\circ}$ transitorio de la Ley 19.640, Orgánica Constitucional del Ministerio Público. El artículo 483 dispone que "Las disposiciones de este Código solo se aplicarán a los hechos acaecidos con posterioridad a su entrada en vigencia”. El artículo 484, ya señalado, establece que "En consecuencia, regirá para las regiones de Coquimbo y de la Araucanía, desde el 16 de diciembre de 2000; para las regiones de Antofagasta, Atacama y del Maule, desde el 16 de octubre de 2001; para las regiones de Tarapacá, de Aisén del General Carlos Ibáñez del Campo y de Magallanes y de la Antártica Chilena, desde el 16 de diciembre de 2002; para las regiones de Valparaiso, del Libertador General Bernardo O'Higgins, del Bío Bío y de Los Lagos, desde el 16 de diciembre de 2003, y para la Región Metropolitana de Santiago, desde el 16 de junio de 2005".

La ley contempla una regla en materia de competencia territorial que adquiere importancia en cuanto a la oportunidad en que se comete el delito: "Se entiende cometido el delito donde se hubiere dado principio a su ejecución" (art. 157 del COT). Parafraseando la norma diremos que "Se entiende cometido el delito cuando se hubiere dado principio a su ejecución" 59 .

59 Esta aseveración solo pretende ser válida para el efecto de determinar el tribunal competente. 
El Ministerio Público debe investigar hechos, y conforme lo señala el artículo $4^{\circ}$ transitorio de la Ley Orgánica del Ministerio Publico, "las normas que autorizan al Ministerio Público para ejercer la acción penal pública, dirigir la investigación y proteger a las víctimas y los testigos, entrarán en vigencia con la gradualidad que el artículo señala”.

Por otra parte, el Código Procesal Penal, en su artículo 483 señala que las disposiciones de este Código solo se aplicarán a los hechos acaecidos con posterioridad a su entrada en vigencia.

Lo importante para determinar la competencia, no es cuándo se perfecciona el delito; lo relevante es cuándo principia la ejecución del delito. Los hechos acaecidos con anterioridad a la vigencia de la reforma procesal penal son de competencia de los antiguos juzgados del crimen y los acaecidos con posterioridad serán de competencia de los nuevos tribunales.

Como es posible advertir, no se trata aquí de una cuestión relativa a la materia, al grado, al fuero, a la cuantía, sino a la oportunidad o época en que ocurrieron los hechos ${ }^{60}$, lo que conforma un nuevo factor de la competencia absoluta.

Se podrá afirmar que este elemento de la competencia es transitorio, en tanto terminará de aplicarse cuando las causas del antiguo sistema procesal terminen. Si bien ello es cierto, se debe reconocer que es posible que los antiguos tribunales sigan conociendo de delitos cometidos con anterioridad a la entrada en vigencia del nuevo sistema, lo que ocurrirá en cuanto se cumplan los plazos de prescripción. Que, aún cumpliéndose dicho plazo, la declaración de prescripción le corresponde al juez competente para conocer de las causas y que hay acciones imprescriptibles en materia penal. El plazo máximo de prescripción en asuntos penales es de 15 años, pero que puede elevarse al doble si tiene aplicación la norma del artículo 100 del Código Penal.

\section{8) EL PROCEDIMIENTO COMO ELEMENTO DE LA COMPETENCIA}

\subsection{1) Planteamiento de la cuestión}

\section{a. En los asuntos civiles}

Tendemos a afirmar que la competencia en materias civiles les corresponde a los juzgados de letras ${ }^{61}$ ya que así se establece en el artículo 45

60 Maturana Miquel, Cristian (2004): “Derecho Procesal Orgánico. Tomo I. Parte General. Las Formas de Solución del Conflicto, el Derecho Procesal, La Jurisdicción y la Competencia”. Disponible en: <http://apuntesderecho1.googlepages.com/M11.R.OrganosJurisdiccionales_2004.pdf > [fecha de consulta: 19 de septiembre de 2012] considera como elemento de la competencia absoluta "por la entrada en vigencia gradual de la ley procesal penal, el factor tiempo para aquellas materias” (MATurana (2004) 64).

61 Salvo el caso en que por concurrir alguna parte con fuero, el asunto deba ser conocido por un Ministro de Corte de Apelaciones, conforme al artículo 50 del Código Orgánico de Tribunales. 
del Código Orgánico de Tribunales, pero dicha regla admite excepciones en nuestro sistema procesal, que son las siguientes:

$1^{\circ}$ De acuerdo a la Ley 18.287 que "Establece procedimiento ante los Juzgados de Policía Local", estos tribunales son competentes "para conocer de la acción civil, siempre que se interponga, oportunamente, dentro del procedimiento contravencional" (artículo 90).

$2^{\circ}$ Los Juzgados del Crimen en el antiguo procedimiento penal tenían competencia para conocer las pretensiones civiles "para perseguir las responsabilidades civiles provenientes del hecho punible... (y la que tenga) por objeto la mera restitución de una cosa" (artículo $5^{\circ}$ del Código de Procedimiento Penal). La pretensión civil se puede entablar no solo contra los responsables del hecho punible, sino también contra los terceros civilmente responsables y contra los herederos de unos y otros (artículo 40 del Código de Procedimiento Penal). Los artículos 425 y siguientes del Código de Procedimiento Penal reglan la manera en que se ejercen las acciones civiles en el procedimiento penal lo que puede ocurrir en la etapa de plenario.

$3^{\circ}$ En el marco del actual proceso penal, tanto los Juzgados de Garantía como los Tribunales de Juicio Oral en lo Penal tienen competencia para conocer de la pretensión civil que tuviere por objeto únicamente la restitución de la cosa y para conocer de las acciones deducidas por la víctima respecto del imputado que tuvieren por objeto perseguir las responsabilidades civiles derivadas del hecho punible (art. 59 y 393, inciso segundo, del Código Procesal Penal). En todo caso, la competencia del juez de garantía solo en materia civil alcanza para conocer de los incidentes y excepciones deducidos con ocasión de la interposición o contestación de la demanda (art. 63 del Código Procesal Penal), de la conciliación (art. 273 del Código Procesal Penal) y del cumplimiento de las obligaciones civiles pactadas en el acuerdo reparatorio (art. 243 del Código Procesal Penal). El tribunal de juicio oral en lo penal conoce del fondo de la pretensión y de los incidentes que se promuevan durante el curso del juicio hasta la dictación de la sentencia definitiva.

Las disposiciones legales citadas son concordantes con la norma del artículo 171 del Código Orgánico de Tribunales que "La acción civil que tuviere por objeto únicamente la restitución de la cosa, deberá interponerse siempre ante el tribunal que conozca las gestiones relacionadas con el respectivo procedimiento penal.

Dicho tribunal conocerá también todas las restantes acciones que la victima deduzca respecto del imputado para perseguir las responsabilidades civiles derivadas del hecho punible, y que no interponga en sede civil'.

Se puede observar, en consecuencia, que además de los Juzgados de Letras, tanto los Juzgados de Policía Local, como los Juzgados del Crimen y los Tribunales de Juicio Oral en lo Penal tienen competencia para conocer de cuestiones civiles, aunque los últimos tres acotadas a pretensiones 
de indemnización de perjuicios que nacen como resultado de la infracción a las normas de que conocen como parte de su competencia principal. Tratándose de estas pretensiones la ley otorga opciones de tribunal competente que no se pueden definir a partir de este exclusivo factor de competencia.

El factor fuero puede modificar la opción generando, como alternativa al Juzgado de Letras, que sea un Ministro de la Corte de Apelaciones respectiva quien conozca la pretensión cuando actúe como parte en el proceso uno de aquellos que tienen la investidura que el artículo 50 No 2 del Código Orgánico de Tribunales indica ${ }^{62}$, pero manteniéndose básicamente la alternativa de tribunales.

El factor cuantía ni acota ni modifica las opciones.

Pues bien, si, como he dicho, los factores de competencia deben ser capaces por sí solos de explicar la distribución de la competencia jurisdiccional entre los distintos tribunales, y la materia, el fuero, el grado, la cuantía ni los demás factores analizados, no logran dilucidar cuál es el tribunal competente, esto quiere decir que hay otro factor o elemento de la competencia que no ha sido descifrado por la doctrina que ha de resolver la disyuntiva.

\section{b. En los asuntos penales}

A partir del año 2000, en el ámbito penal, utilizando únicamente el factor materia y solo considerando aquellos tribunales que operan en el nuevo proceso penal, podemos determinar que existen dos tribunales competentes para conocer de estas cuestiones que son los Juzgados de Garantía y los Tribunales de Juicio Oral en lo Penal. Los artículos 14, inciso segundo, y 18 del Código Orgánico de Tribunales precisan la competencia de ambos tribunales ${ }^{63}$. En consecuencia, existen dos clases de tribunales para conocer de los conflictos penales, de manera que el factor materia

62 La norma del artículo 50 No 2 del Código Orgánico de Tribunales dispone "Art. 50. Un ministro de la Corte de Apelaciones respectiva, según el turno que ella fije, conocerá en primera instancia de los siguientes asuntos:

$2^{\circ}$. De las causas civiles en que sean parte o tengan interés el Presidente de la República, los ex Presidentes de la República, los Ministros de Estado, Senadores, Diputados, miembros de los Tribunales Superiores de Justicia, Contralor General de la República, Comandantes en Jefe de las Fuerzas Armadas, General Director de Carabineros de Chile, Director General de la Policía de Investigaciones de Chile, los Intendentes y Gobernadores, los Agentes Diplomáticos chilenos, los Embajadores y los Ministros Diplomáticos acreditados con el Gobierno de la República o en tránsito por su territorio, los Arzobispos, los Obispos, los Vicarios Generales, los Provisores y los Vicarios Capitulares.

La circunstancia de ser accionista de sociedades anónimas las personas designadas en este número, no se considerará como una causa suficiente para que un ministro de la Corte de Apelaciones conozca en primera instancia de los juicios en que aquéllas tengan parte, debiendo éstos sujetarse en su conocimiento a las reglas generales.

63 El inciso segundo del artículo 14 del Código Orgánico de Tribunales dispone que "Corresponderá a los jueces de garantía: 
nos permite únicamente descartar como opción a otros tribunales, pero no resuelve por sí solo cuál es la clase de tribunal competente para conocer del asunto.

El fuero como factor de competencia no es actualmente aplicable en materia penal.

La cuantía, aunque recobra importancia como factor de competencia en materia penal, no resuelve el problema como paso a detallar.

En los asuntos criminales la cuantía se determina por la pena que el delito lleva consigo (art. 115 del Código Orgánico de Tribunales). Los delitos se clasifican según sus penas, conforme se establece en el artículo 21 del Código Penal, en: faltas, simples delitos y crímenes. Tratándose de las penas privativas de libertad, que son las más habituales en el ordenamiento penal, las penas de falta llegan hasta 60 días; las de simples delitos desde 61 días a 5 años y las de crímenes desde 5 años y 1 día hasta presidio perpetuo calificado.

En el ámbito penal, la cuantía unida a la materia permitiría determinar la clase o jerarquía del tribunal competente solo en algunos casos, supuesto que el Fiscal solicite la imposición de una pena. Estos casos serían los siguientes:

1) El conocimiento de las faltas: es siempre de competencia del juez de garantía.

a) Asegurar los derechos del imputado y demás intervinientes en el proceso penal, de acuerdo a la ley procesal penal;

b) Dirigir personalmente las audiencias que procedan, de conformidad a la ley procesal penal;

c) Dictar sentencia, cuando corresponda, en el procedimiento abreviado que contemple la ley procesal penal;

d) Conocer y fallar las faltas penales de conformidad con el procedimiento contenido en la ley procesal penal;

e) Conocer y fallar, conforme a los procedimientos regulados en el Título I del Libro IV del Código Procesal Penal, las faltas e infracciones contempladas en la Ley de Alcoholes, cualquiera sea la pena que ella les asigne;

f) Hacer ejecutar las condenas criminales y las medidas de seguridad, y resolver las solicitudes y reclamos relativos a dicha ejecución, de conformidad a la ley procesal penal;

g) Conocer y resolver todas las cuestiones y asuntos que la ley de responsabilidad penal juvenil les encomienden, $y$

b) Conocer y resolver todas las cuestiones y asuntos que este Código, la ley procesal penal y la ley que establece disposiciones especiales sobre el Sistema de Justicia Militar les encomienden.

El artículo 18 del mismo texto legal dispone: "Art. 18.- Corresponderá a los tribunales de jucio oral en lo penal:

a) Conocer y juzgar las causas por crimen o simple delito, salvo aquellas relativas a simples delitos cuyo conocimiento y fallo corresponda a un juez de garantía;

b) Resolver, en su caso, sobre la libertad o prisión preventiva de los acusados puestos a su disposición;

c) Resolver todos los incidentes que se promuevan durante el juicio oral;

d) Conocer y resolver todas las cuestiones y asuntos que la ley de responsabilidad penal juvenil les encomienden, $y$

e) Conocer y resolver los demás asuntos que la ley procesal penal y la ley que establece disposiciones especiales sobre el Sistema de Justicia Militar les encomiende. 
2) El conocimiento de los simples delitos, si el Fiscal solicita una pena no superior a 540 días de privación de libertad, es siempre de competencia del juez de garantía.

Tratándose de simples delitos en que el Fiscal solicite la imposición de una pena superior a 540 días de privación de libertad y en el caso de crímenes, deberán conocer de la causa tantos los Juzgados de Garantía como los Tribunales de Juicio Oral en lo Penal, por lo que la cuantía no resuelve en dichos casos la controversia.

He dicho que la cuantía, junto a la materia, resuelve la competencia en estos casos, siempre que el Fiscal solicite la imposición de una pena; pero ocurre que el proceso penal se utiliza también para decidir sobre la imposición de medidas de seguridad respecto de quien es inimputable debido a enajenación mental. Si consideramos estos casos, la cuantía no resuelve cuál es el tribunal competente para asuntos penales entre los Juzgados de Garantía y los Tribunales de Juicio Oral en lo Penal, ya que ambos tienen competencia para conocer de los casos en que se pretende la imposición de medidas de seguridad, independientemente de la cuantía.

Nuevamente los factores de competencia materia, fuero y cuantía resultan insuficientes para resolver cuál es la clase de tribunal competente.

\section{c. En los asuntos laborales}

En los asuntos laborales, a partir de la reforma procesal laboral, además de modificarse el procedimiento laboral se crearon dos tribunales: los Juzgados de Letras del Trabajo y los Juzgados de Cobranza Laboral y Previsional. La competencia de los Juzgados de Letras del Trabajo está definida en el artículo 420 del Código del Trabajo ${ }^{64}$ y la

64 La norma señala: "Art. 420. Serán de competencia de los Juzgados de Letras del Trabajo:

a) las cuestiones suscitadas entre empleadores y trabajadores por aplicación de las normas laborales o derivadas de la interpretación y aplicación de los contratos individuales o colectivos del trabajo o de las convenciones y fallos arbitrales en materia laboral;

b) las cuestiones derivadas de la aplicación de las normas sobre organización sindical y negociación colectiva que la ley entrega al conocimiento de los juzgados de letras con competencia en materia del trabajo;

c) las cuestiones derivadas de la aplicación de las normas de previsión o de seguridad social, planteadas por pensionados, trabajadores activos o empleadores, salvo en lo referido a la revisión de las resoluciones sobre declaración de invalidez o del pronunciamiento sobre otorgamiento de licencias médicas;

d) los juicios en que se demande el cumplimiento de obligaciones que emanen de titulos a los cuales las leyes laborales y de previsión o seguridad social otorguen mérito ejecutivo;

e) las reclamaciones que procedan contra resoluciones dictadas por autoridades administrativas en materias laborales, previsionales o de seguridad social;

f) los juicios en que se pretenda hacer efectiva la responsabilidad del empleador derivada de accidentes del trabajo o enfermedades profesionales, con excepción de la responsabilidad extracontractual a la cual le será aplicable lo dispuesto en el artículo 69 de la ley $N^{\circ} 16.744, y$

g) todas aquellas materias que las leyes entreguen a juzgados de letras con competencia laboral. 
de los Juzgados de Cobranza Laboral y Previsional en el artículo 421 del mismo texto legal ${ }^{65}$.

Tanto los Juzgados de letras del Trabajo como los Juzgados de cobranza laboral y Previsional tienen conocimiento de los litigios en materia laboral y previsional, por lo que la materia es insuficiente como elemento para explicar la forma en que se distribuye la competencia entre ambos, por cuanto conocerán del mismo tipo de conflictos e, incluso, de los mismos conflictos solo que en momentos jurisdiccionales distintos.

\subsection{2) Ámbito Civil}

$\mathrm{Si}$, como hemos visto, los Juzgados de Letras y, en su caso, los Ministros de Cortes de Apelaciones, comparten o compartían en parte la competencia en materias civiles con los Juzgados del Crimen, los Juzgados de Policía Local, los Juzgados de Garantía y los Tribunales de Juicio Oral en lo Penal; y los elementos tradicionales de la competencia no sirven para determinar cuál es el tribunal competente para conocer del asunto, es evidente que existe otro factor con el cual ha de realizarse esa determinación.

En efecto, la materia, en estos casos, solo permite descartar la competencia de ciertas clases de tribunales, pero no permite determinar la clase exacta de tribunal competente entre los tribunales que hemos definido en esta "disputa". El fuero, en algún caso, de concurrir, podría resolver la cuestión, pero en otros resulta inaplicable. Por su parte, la cuantía resulta irrelevante en esta problemática.

Hay que asumir que tanto los tribunales que conocen materias penales como los que conocen materias infraccionales tienen cierta competencia en materia civil como una concesión legislativa a la economía procesal. No se trata de convertirlos en tribunales civiles, sino de dotarlos de cierta competencia en este ámbito solo en cuanto conocen de un conflicto a partir del cual se pueden reclamar pretensiones civiles. Un requisito sine qua non para que estos tribunales puedan conocer de estas pretensiones consiste, en consecuencia, en que conozcan del conflicto penal o infraccional que sirve de fundamento a la pretensión civil y que esta se deduzca dentro del mismo proceso penal o infraccional. Estos requisitos se contemplan en las normas del respectivo procedimiento penal o infraccional. No se trata, por lo tanto, de otorgar competencia en materia civil de ma-

65 Artículo 421. Serán de competencia de los Juzgados de Cobranza Laboral y Previsional los juicios en que se demande el cumplimiento de obligaciones que emanen de titulos a los cuales las leyes laborales y de previsión o seguridad social otorguen mérito ejecutivo; $y$, especialmente, la ejecución de todos los títulos ejecutivos regidos por la ley $N^{\circ} 17.322$, relativa a la cobranza judicial de imposiciones, aportes y multas en los institutos de previsión.

Con todo, el conocimiento de las materias señaladas en el inciso anterior, solo corresponderá a los Juzgados de Letras del Trabajo en aquellos territorios jurisdiccionales en que no existan Juzgados de Cobranza Laboral y Previsional. 
nera indiscriminada, sino que vinculada al procedimiento que se utilice. Por esto, se puede decir que la competencia civil relativa a la pretensión indemnizatoria la tienen (o tenían) los Juzgados del Crimen, los Juzgados de Policía Local, los Juzgados de Garantía y los Tribunales de Juicio Oral en lo Penal cuando la pretensión se deducía en el respectivo procedimiento penal o infraccional; y la tienen los Juzgados de Letras cuando la pretensión se deduce en el procedimiento civil.

El procedimiento permite resolver la problemática que hemos planteado en relación a las cuestiones civiles, pero quedan aún por resolver las que se manifiestan en el ámbito penal y laboral.

\subsection{3) Ámbito Penal}

En el ámbito penal, he explicado la dificultad que existe para determinar la clase de tribunal competente cuando se recurre únicamente a los factores tradicionales de la competencia absoluta que, en definitiva, no logran discriminar entre los Juzgados de Garantía y los Tribunales de Juicio Oral en lo Penal.

En el marco del procedimiento penal, corresponde al juez de garantía conocer de todos los casos en la etapa de investigación y en la etapa intermedia. Más aún, en la etapa de adjudicación en la que corresponde resolver sobre la condena o absolución del imputado, el juez de garantía será igualmente competente en la medida en que el asunto se resuelva por algún procedimiento especial: monitorio, simplificado, abreviado o juicio oral simplificado. Solo cuando el imputado ejerce su derecho a juicio oral y el Fiscal solicita la imposición de una pena superior a 541 días de privación de libertad; o bien, el Fiscal solicita la imposición de una pena superior a cinco ańos de privación de libertad; o solicita la imposición de una medida de seguridad contra el imputado enajenado mental ${ }^{66}$, el asunto será conocido por el tribunal de juicio oral en lo penal.

De esta manera, respecto de un mismo asunto, sobre la misma materia y por la misma cuantía, es posible que existan dos tribunales competentes: el juzgado de garantía y el tribunal de juicio oral en lo penal. Serán competentes ambos, pero en distintas fases del procedimiento, el primero, en la etapa de investigación, en la etapa intermedia y en la etapa de ejecución; el segundo, en la etapa de juicio oral, siempre que corresponda someter el asunto a este procedimiento y no a un procedimiento especial.

66 En el caso que el Fiscal solicite una pena superior a 5 años de privación de libertad, la ley procesal chilena no permite una forma distinta de resolución del asunto que no sea el juicio oral ordinario de que conoce el tribunal de juicio oral en lo penal. Del mismo modo, la medida de seguridad solo puede imponerse a través del juicio oral ordinario. 
La cuestión a definir es sobre cuál es el elemento o factor que determinará la clase de tribunal que va a conocer del asunto. La respuesta es clara y viene dada por las explicaciones precedentes. En los asuntos penales el procedimiento a aplicar es el que determina, en los casos no resueltos por la materia y la cuantía, la clase del tribunal que va a conocer del proceso.

En función del procedimiento se puede distinguir la competencia de los tribunales conforme al siguiente esquema:

$1^{\circ}$ Procedimiento de control de investigación y de preparación del juicio oral: es competente el juzgado de garantía;

$2^{\circ}$ Procedimiento monitorio: es competente el juzgado de garantía;

$3^{\circ}$ Procedimiento simplificado de admisión de responsabilidad: es competente el juzgado de garantía;

$4^{\circ}$ Procedimiento abreviado: es competente el juzgado de garantía;

$5^{\circ}$ Juicio oral simplificado: es competente el juzgado de garantía;

$6^{\circ}$ Juicio oral ordinario: es competente el tribunal de juicio oral en lo penal; $y$,

$7^{\circ}$ Procedimiento de ejecución de las condenas criminales y de las medidas de seguridad: es competente el juzgado de garantía.

Como se puede observar, si se hiciera abstracción de la cuantía, la materia y el procedimiento serían suficientes para determinar la clase de tribunal competente para conocer de los asuntos en materia penal. Lo que ocurre es que la cuantía resulta en estos casos necesaria para establecer el procedimiento aplicable, particularmente en la etapa de adjudicación, ya que el juzgado de garantía es siempre competente para conocer del procedimiento de control de investigación y de preparación del juicio oral. Así, conforme al siguiente esquema podemos determinar el procedimiento aplicable:

$1^{\circ}$ Tratándose de faltas en que se solicita únicamente la imposición de la pena de multa corresponde aplicar el procedimiento monitorio;

$2^{\circ}$ Tratándose de faltas respecto de las que no sea procedente el procedimiento monitorio y el imputado renunciare a su derecho a juicio oral corresponde aplicar el procedimiento simplificado de admisión de responsabilidad;

$3^{\circ}$ Tratándose de faltas respecto de las que se rechazare por el juez el procedimiento monitorio o se reclamare contra el requerimiento o contra la multa por el imputado, procederá el juicio oral simplificado;

$4^{\circ}$ Tratándose de simples delitos respecto de los que el Fiscal requiriere la imposición de penas no superiores a 540 días de privación de libertad y el imputado renunciare a su derecho a juicio oral corresponde aplicar el procedimiento simplificado de admisión de responsabilidad;

$5^{\circ}$ Tratándose de simples delitos respecto de los que el Fiscal requiriere la imposición de penas no superiores a 540 días de privación de libertad y el imputado ejerciere su derecho a juicio oral corresponde aplicar el juicio oral simplificado; 
$6^{\circ}$ Tratándose de simples delitos respecto de los que el Fiscal requiriere la imposición de penas superiores a 540 días de privación de libertad y el imputado renunciare a su derecho a juicio oral corresponde aplicar el procedimiento abreviado;

$7^{\circ}$ Tratándose de simples delitos respecto de los que el Fiscal requiriere la imposición de penas superiores a 540 días de privación de libertad y el imputado ejerciere su derecho a juicio oral corresponde aplicar el juicio oral ordinario;

$8^{\circ}$ Tratándose de crímenes respecto de los que el Fiscal requiriere la imposición de penas no superiores a 5 años de privación de libertad y el imputado renunciare a su derecho a juicio oral corresponde aplicar el procedimiento abreviado;

$9^{\circ}$ Tratándose de crímenes respecto de los que el Fiscal requiriere la imposición de penas no superiores a 5 años de privación de libertad y el imputado ejerciere su derecho a juicio oral corresponde aplicar el juicio oral ordinario; $y$

$10^{\circ}$ Tratándose de crímenes respecto de los que el Fiscal requiriere la imposición de penas superiores a 5 años de privación de libertad corresponde aplicar el juicio oral ordinario.

En el caso de que el Fiscal solicite la imposición de medidas de seguridad, la cuantía no es relevante ya que el procedimiento de adjudicación siempre será el juicio oral, independientemente del delito que la fundamente.

\subsection{4) Ámbito Laboral y Previsional}

Lo que ocurre en el ámbito penal, en cuanto que existen dos tribunales que son competentes para conocer de la misma materia, ocurre también en el ámbito de los asuntos laborales y previsionales. En estas materias tampoco es aplicable el fuero y la cuantía no es considerada como elemento de la competencia por el legislador. Sin embargo, la materia resulta insuficiente para determinar la clase y jerarquía del tribunal ya que son dos los tribunales que tienen competencia para conocer de la misma materia: los Juzgados de Letras del Trabajo y los Juzgados de Cobranza Laboral y Previsional.

El procedimiento a aplicar será el que determine la clase de tribunal que conocerá del conflicto laboral. Los juzgados de letras del trabajo son tribunales que conocerán de los procedimientos declarativos, mientras que los Juzgados de cobranza laboral y previsional conocerán de procedimientos ejecutivos exclusivamente.

\section{9) LA PREVENCIÓN}

Ovalle Favela señala que "La prevención es un criterio complementario y subsidiario para determinar competencia, pues se suele recurrir a 
él cuando, de acuerdo con los criterios anteriores, varios jueces son competentes para conocer de forma simultánea del mismo asunto; entonces se afirma que será competente el que haya prevenido en la causa, es decir, el que haya conocido primero" ${ }^{67}$. Alvarado Velloso denomina a este criterio competencia prevencional ${ }^{68}$.

La norma del artículo 111 del Código Orgánico de Tribunales contempla el criterio de prevención, el que ha sido entendido por la doctrina nacional como una regla general de la competencia. La norma señala: "Siempre que según la ley fueren competentes para conocer de un mismo asunto dos o más tribunales, ninguno de ellos podrá excusarse del conocimiento bajo el pretexto de haber otros tribunales que puedan conocer del mismo asunto; pero el que haya prevenido en el conocimiento excluye a los demás, los cuales cesan desde entonces de ser competentes".

En el evento de una contienda de competencia entre dos tribunales que parecen ser igualmente competentes, la prevención actúa como un criterio decisivo para dirimirla, por lo que en propiedad no es un criterio de asignación de competencia.

\section{4) COMPETENCIA ABSOLUTA Y RELATIVA}

La doctrina tradicional en Chile clasifica la competencia en cuanto a la determinación del tribunal competente ${ }^{69}$, o bien, atendiendo a los factores que la determinan ${ }^{70}$, en absoluta y relativa. Así, competencia absoluta es aquella que determina la clase y, eventualmente, la jerarquía del tribunal llamado por ley a conocer de un asunto determinado; y la competencia relativa es aquella que determina qué tribunal, dentro de una clase o jerarquía es el que debe conocer del asunto concreto que se desea plantear y someter a su resolución. Los elementos que determinarían la competencia absoluta son la materia, el fuero y la cuantía; mientras que la competencia relativa está determinada por el territorio ${ }^{71}$.

Repasando las características de la competencia absoluta esbozadas por la doctrina nacional, se dice que esta permite el reparto de la jurisdicción entre las diversas clases y jerarquías de tribunales que existen en el país; son reglas de orden público; son irrenunciables por las partes y obligatorias para el juez; su infracción puede alegarse en cualquier tiempo de acuerdo a las reglas de procedimiento; puede y debe declararse

Ovalle (2010) 142.

Alvarado (2011) 137.

Según la explicación de Maturana (2004) 64.

Explicación de Colombo (2004) 154

Véase los textos de Pereira (1993); Casarino (1995); Colombo (2004); Hermosilla (2006); Salas (2006); Díaz (2006); Orellana (2010); Chávez (2008); y Correa (2012). 
de oficio por el tribunal; los elementos que determinan la competencia absoluta son, como ya se dijo, la materia, la persona o fuero y la cuantía; constituye un presupuesto de la regla de radicación; y, se sanea con la cosa juzgada $^{72}$. Por su parte, en relación a la competencia relativa, la doctrina señala como sus características que se trata, por lo general, de normas de orden privado; admiten prórroga; solo puede alegarse incompetencia relativa dentro del plazo para oponer la excepción dilatoria correspondiente; su misión es determinar con precisión cuál es el tribunal competente para conocer del proceso y su elemento determinante es el territorio; y, da eficacia a la garantía constitucional de acceso a la justicia.

En la doctrina comparada, la clasificación entre competencia absoluta o relativa tiene una significación que gira en torno a una lógica distinta de la que se le atribuye en Chile. Así, Palacio explica que esta clasificación se realiza "según que admita o no ser prorrogada o renunciada por las partes". Ya Chiovenda señalaba que "Los límites de la jurisdicción ${ }^{73}$ son pues prorrogables (o relativos o dispositivos), o improrrogables (absolutos, necesarios), según que admitan o no su observancia, según que influyen o no en la voluntad de las partes"74.

La denominación de absoluta o relativa de estos tipos de competencia no emerge, en consecuencia, de los factores de competencia, sino de una decisión legislativa que determina que en algunos casos los factores determinantes de la competencia rigen de modo absoluto y, en otros, de modo relativo; en otros términos, a que en los primeros las partes y el juez deben someterse a la competencia definida por la ley; y, a que en los segundos las partes pueden modificar esa determinación.

En todo caso, se entiende claramente la asociación que se ha hecho en Chile entre competencia absoluta y los factores de competencia materia, fuero y cuantía; y entre competencia relativa y el factor territorio, en atención a que, en relación a los primeros factores la ley no admite prórroga de competencia y sí lo hace respecto del factor territorio, como ocurre igualmente en otras legislaciones. Alsina, al respecto, explica que "De la circunstancia de que la competencia territorial se determina por el domicilio de la persona o la situación de la cosa, dedúcese que ella es relativa y, por consiguiente, renunciable por las partes; mientras que la competencia por materia, valor, turno y grado es absoluta, porque se funda en

Соцомво (2004) 175 y ss.

Hoy en día resulta impropio hablar de "límites de la jurisdicción" en este contexto, sino que es más propio referirse a los "Límites de la competencia".

74 Chiovenda (1922) 601. 
una división de funciones que afecta el orden público y, por lo tanto, no modificables por las partes ni por el juez."75-76

PAlACIO, siguiendo a LASCANO, agrega que "no media ninguna razón de orden esencial para que cada una de las clases de competencia a las que se ha hecho mención precedentemente ${ }^{77}$ deba ser necesariamente adscripta a alguna de esas categorías, pues en definitiva solo el texto de la ley puede servir de pauta válida para establecer si determinada clase de competencia es o no prorrogable"78. De hecho, en Chile, el territorio tiene un tratamiento distinto según el ámbito de que se trate. Así, en el ámbito civil es prorrogable; sin embargo, en el ámbito penal, no lo es. De lo seńalado, debe concluirse que en el ámbito procesal civil el territorio es un factor de competencia relativa, mientras que en el marco procesal penal es de competencia absoluta, según la manera de entenderse esta clasificación en el derecho comparado.

Colombo, como el resto de la doctrina, concuerda en que en materia penal no es posible la prórroga de competencia. El autor cita al efecto el artículo $9^{\circ}$ del Código de Procedimiento Penal que dispone que "La competencia criminal no puede, en caso alguno, ser prorrogada por la simple voluntad de las partes". La disposición citada no se contiene en una norma similar en el Código Procesal Penal, aunque es posible concluir la misma idea con la norma imperativa del artículo $2^{\circ}$ que dice: "Juez natural. Nadie podrá ser juzgado por comisiones especiales, sino por el tribunal que señalare la ley y que se hallare establecido por esta con anterioridad a la perpetración del hecho". Sin embargo, el referido autor al clasificar la competencia en natural y prorrogada señala "Ya vimos que el Título III del Código Procesal Penal, al autorizar a las partes en su artículos 406, 408 y 409, a otorgar competencia al juez de garantía en el procedimiento abreviado y no acceder al tribunal normal, que es el tribunal de juicio oral en lo penal, está prorrogando competencia del uno al otro"79.

En verdad, cuando en el proceso penal las partes convienen en el procedimiento abreviado no tienen en vistas la prórroga de competencia sino un pacto mucho más sustancial que dice relación con el reconocimiento de hechos, la pena máxima que el juez puede imponer y el procedimiento que será aplicable para resolver el conflicto. Acordado el procedimiento abreviado las partes no pueden elegir el tribunal que conocerá

\footnotetext{
75 Alsina (1957) 515.

76 Alsina (1957): señala que "Más exacto sería decir que la competencia es relativa cuando se determina con relación a una persona determinada (como la territorial) y por ello renunciable por aquélla; y absoluta cuando se determina con prescindencia de las personas (por la materia, valor o grado) y por consiguiente de orden público" 515.

77 Se refiere a la clasificación sobre la base de los criterios territorial, objetiva, funcional y personal, sobre los que me referiré más adelante.

78 Palacio (2003) 193.

79 Colombo (2004) 138.
} 
del conflicto, sino que es la ley la que lo determina. La prórroga de competencia es un pacto que dice relación exclusivamente con la competencia del tribunal de modo que el acuerdo sobre el procedimiento abreviado no puede ser llamado prórroga de competencia.

Más aún, Alsina sostiene que la clasificación entre absoluta y relativa no es propiamente una clasificación de la competencia sino de la incompetencia, "y así se dice que un juez tiene incompetencia relativa cuando la persona demandada o la cosa objeto del litigio están fuera de su circunscripción territorial, porque su incompetencia nace de una circunstancia relativa a la persona o a la cosa, en tanto que tiene incompetencia absoluta para conocer de una cuestión por materia, con independencia de la persona o del objeto litigioso" 80 .

\section{5) CONCLUSIONES}

$1^{\circ}$ Los elementos o factores de la competencia son los criterios conforme a los cuales la ley distribuye el ejercicio de la jurisdicción entre los tribunales establecidos por ella.

$2^{\circ}$ Los factores de competencia deben estar fijados por ley para resguardar el derecho al juez predeterminado que exige que el tribunal debe existir antes de la ocurrencia del hecho que origina el conflicto y que su competencia debe igualmente estar determinada antes de la ocurrencia de ese hecho.

$3^{\circ}$ Para satisfacer este derecho los factores de competencia deben ser tales que permitan determinar de modo exacto y preciso el tribunal competente para conocer de un conflicto o establecer las bases para que ese tribunal sea determinado a fin de asegurar "la inderogabilidad y la indisponibilidad de las competencias, esto es, la reserva absoluta de ley y la no alterabilidad discrecional de las competencias judiciales".

$4^{\circ} \mathrm{La}$ enseñanza tradicional en Chile nos indica que los criterios para distribuir el ejercicio de la jurisdicción son cuatro: materia, fuero, cuantía y territorio, pero estos factores son insuficientes para explicar cómo se distribuye en Chile el ejercicio de la jurisdicción.

$5^{\circ} \mathrm{El}$ grado, entendido como todo conocimiento del proceso que realiza un tribunal de distinta jerarquía activado por la interposición de un recurso, es un criterio de distribución del ejercicio de la jurisdicción presente en nuestro orden procesal, que permite discriminar entre tribunales de distinta jerarquía.

$6^{\circ}$ No obstante los cuestionamientos de parte de la doctrina, el turno, entendido como "un sistema de distribución de los asuntos nue-

Alsina (1957) 515. 
vos entre diversos órganos jurisdiccionales, ya sea en razón del orden de presentación de dichos asuntos o en razón de la fecha en la cual estos se inician" ${ }^{81}$; es también un factor o elemento de la competencia, que permite discriminar entre tribunales que conocen de causas sobre las mismas materias, en el mismo grado, misma cuantía y mismo territorio.

$7^{\circ} \mathrm{La}$ atracción que "Consiste en la acumulación que debe realizarse de los juicios singulares que se sigan contra una persona, al juicio universal que se promueva en caso de que dicha persona fallezca (juicio sucesorio), o sea declarada en estado de insolvencia (juicio de concurso mercantil, si es comerciante, o de concurso civil, si no lo es)" 82 es también un factor de competencia. La atracción determina en muchos casos la modificación de la competencia que tiene un tribunal respecto del proceso singular, el que deja de ser competente para pasar a serlo el tribunal que conoce del proceso universal.

$8^{\circ}$ El criterio de la conexidad como factor de competencia "se presenta cuando dos o más procesos comparten elementos en común, ya sea la causa petendi o el objeto -en cuyo caso se le conoce como conexidad objetiva-, o bien, litigan las mismas partes - conexidad subjetiva-" 83 . El efecto de la conexidad es la acumulación de los procesos que "consiste en la reunión en un solo proceso de todos los juicios que se estaban tramitando separadamente, cuando el fallo de uno de ellos deba producir cosa juzgada en el o los otros; o cuando se cumplan otros requisitos que los Códigos de Procedimiento Civil o Penal se encargan de establecer" ${ }^{84}$. La competencia de los tribunales es modificada, aun cuando el conocimiento del asunto esté radicado en uno de ellos, correspondiendo solo a uno seguir conociendo del caso.

$9^{\circ}$ La elección es un criterio de la competencia cuando expresamente la ley permite que las partes, de común acuerdo, modifiquen la competencia natural del tribunal, superponiendo esa voluntad por sobre la voluntad de la ley; y en los casos en que se dispone que la elección del tribunal competente le corresponde a una de las partes, particularmente al actor, en cuyo caso basta su sola manifestación de voluntad.

$10^{\circ}$ El azar es un criterio de competencia en los casos en que existiendo tribunales alternativos entre los cuales no se puede discriminar sobre la base del interés público, la ley dispone someter la decisión a un sorteo u otro mecanismo que signifique fiar a la suerte tal resolución.

$11^{\circ}$ La oportunidad o época en que ocurrieron los hechos conforma un nuevo factor de la competencia que permite distinguir la competencia entre los tribunales que conocen las causas conforme a las reglas del

Gómez Lara (2004) 150-151.

Ovalle (2010) 141.

Armienta (2003) 69.

Colombo (2004) 154. 
antiguo procedimiento penal y los que conocen las causas conforme a las reglas del nuevo proceso penal.

$12^{\circ}$ El procedimiento es un factor de competencia que permite distinguir la competencia en materia civil entre los juzgados de letras y los que conocen en materias penales e infraccionales; entre los Juzgados de Garantía y los Tribunales de Juicio Oral en lo Penal; y entre los Juzgados de Letras del Trabajo y los Juzgados de Cobranza Laboral y Previsional.

$13^{\circ}$ En el evento de una contienda de competencia entre dos tribunales que parecen ser igualmente competentes, la prevención actúa como un criterio decisivo para dirimirla, cediendo la disputa a favor de aquel tribunal que haya prevenido en el conocimiento, por lo que no es un criterio de asignación de competencia.

$14^{\circ} \mathrm{La}$ clasificación entre competencia absoluta y relativa atiende a la prorrogabilidad del factor de competencia, por lo que no pretende distinguir entre los factores que determinan la clase y jerarquía del tribunal y aquellos que determinan el lugar en que funciona el tribunal de la clase y jerarquía ya determinada. Por lo anterior, el territorio es un factor de competencia relativa en materia civil, pero es de competencia absoluta en materia penal.

\section{BIBLIOGRAFÍA CITADA}

- Alsina, Hugo (1957): Tratado teórico práctico de Derecho Procesal Civil y Comercial, T. II. Organización judicial, jurisdicción y competencia. Buenos Aires: Ediar, 760 pp.

- Alvarado Velloso, Adolfo (2011): Lecciones de Derecho Procesal Civil. Santiago de Chile: Thomson Reuters Puntolex, 844 pp.

- Armienta Calderón, Gonzalo (2003): Teoría general del proceso. Ciudad de México: Editorial Porrúa, 463 pp.

- Caballero, Ana Isabel, y Stippel, Jörg (2003): "Parte II. Jurisprudencia”, en Defensoría Penal Pública (edit.), Manual de Derecho Internacional de los derechos Humanos para Defensores Penales Públicos. Santiago de Chile: Centro de Documentación Defensoría Penal Pública, pp. 103-171.

- Casarino Viterbo, Mario (1995): Manual de Derecho Procesal. Derecho Procesal Orgánico. T. I. Santiago: Editorial Jurídica de Chile, 328 pp.

- Chávez Chávez, Eric Andrés (2008): Derecho Procesal Orgánico y Funcional. Santiago de Chile: Editorial Jurídica Aremi, 490 pp.

- Chiovenda, José (1922): Principios de Derecho Procesal Civil T. I. Traducción de José Casáis y Santaló. Madrid: Editorial Reus, 724 pp.

- Colombo Campbell, Juan (2004): La Competencia. Santiago de Chile: Editorial Jurídica de Chile, 657 pp. 
- Correa Selame, Jorge Danilo (2012): Manual de Derecho Procesal, T. I. Santiago de Chile: Editorial Jurídica Aremi, 365 pp.

- Devis Echandía, Hernando (2012): Teoría General del Proceso. Bogotá: Editorial Temis, 573 pp.

- Díaz Uribe, Claudio (2006): Curso de Derecho Procesal Civil T. I. Santiago de Chile: Abeledo Perrot LegalPublishing Chile - Thomsom Reuters, 397 pp.

- Figueroa Yavar, Juan Agustín y Morgado San Martín, Erika (2013): Jurisdicción, competencia y disposiciones comunes a todo procedimiento. Santiago de Chile: LegalPublishing Chile - Thomsom Reuters, 270 pp.

- Gil SuÁrez, Luis (2001): Jurisdicción y competencia. En Revista del Ministerio de Trabajo y Asuntos Sociales. No 28, pp. 17 a 41.

- Gómez Colomer, Juan Luis (2003): Derecho Jurisdiccional I. Parte General. T. I. Valencia: Editorial Tirant lo Blanch, 486 pp.

- Gómez Lara, Cipriano (2004): Teoría General del Proceso. Ciudad de México: Editorial Oxford, 363 pp.

- Hermosilla Arriagada, Germán (2006): Derecho Procesal Orgánico. Santiago de Chile: Editorial Thomson Reuters Puntolex, 377 pp.

- Lillo Hunzinker, Lenin (1998): “Curso de Derecho Procesal Civil orgánico de tribunales. s. 1.: Ediciones Jurídicas La Ley, 351 pp.

- Luco, Nicolás (2002): "Naturaleza de las reglas del turno y distribución de causas y sanción a su infracción", Revista de Derecho y Jurisprudencia, Tomo XCIX, No 2: pp. 13-28.

- Maturana Miquel, Cristian (2004): "Derecho Procesal Orgánico. Tomo I. Parte General. Las Formas de Solución del Conflicto, el Derecho Procesal, La Jurisdicción y la Competencia”. Disponible en: <http://apuntesderecho1.googlepages.com/M11.R.OrganosJurisdicci onales_2004.pdf > [fecha de consulta: 19 de septiembre de 2012].

- Montero Aroca, Juan (2003): Derecho Jurisdiccional I. Parte General. T. I. Valencia: Editorial Tirant lo Blanch, 486 pp.

- Núñez Ojeda, Raúl y Pérez Ragone, Alvaro (2013): Manual de Derecho Procesal Civil. Parte General. Santiago de Chile: Legal Publishing - Thomsom Reuters, 486 pp.

- Oberg Yáñez, Héctor y Manso Villalón, Macarena (2008): Derecho Procesal Orgánico. Santiago de Chile: LexisNexis - Legal Publishing Chile, 228 pp.

- Orellana Torres, Fernando (2010): Manual de Derecho Procesal, T. I. Santiago de Chile: Editorial Librotecnia, 292 pp.

- Ovalle Favela, José (2010): Teoría General del Proceso. Ciudad de México: Editorial Oxford, 360 pp.

- Pacheco G., Máximo (1990) Teoría del Derecho. $4^{a}$ edición. Santiago: Editorial Jurídica de Chile, 865 pp. 
- Palacio, Lino Enrique (2003): Manual de Derecho Procesal Civil. Buenos Aires: Editorial LexisNexis, 979 pp.

- Pereira Anabalón, Hugo (1993), Curso de Derecho Procesal, Tomo I, Derecho Procesal Orgánico. Santiago de Chile: Editorial Jurídica ConoSur, 480 pp.

- Ramos Méndez, Francisco (1980): Derecho Procesal Civil. Barcelona: Librería Bosch, 1312 pp.

- Redenti, Enrico (1957): Derecho Procesal Civil, T. I. Buenos Aires: Ediciones Jurídicas Europa-América, 511 pp.

- Rocco, Ugo (2002): Derecho Procesal Civil. Ciudad de México: Editorial Jurídica Universitaria, 496 pp.

- Romero Seguel, Alejandro (2009): Curso de Derecho Procesal Civil. Los presupuestos procesales relativos al órgano jurisdiccional. T. I. Santiago: Editorial Jurídica de Chile, $91 \mathrm{pp}$.

- Salas Astraín, Jaime (2006): Iniciación al nuevo Derecho Procesal chileno. Santiago de Chile: Editorial Alfakira, $450 \mathrm{pp}$.

- Vivanco Martínez, Ángela (2006): Curso de Derecho Constitucional, Tomo II. Santiago de Chile: Ediciones Universidad Católica de Chile, 555 pp.

\section{JURISPRUDENCIA CITADA}

- Corte Interamericana de Derechos Humanos, 30 de mayo de 1999. "Castillo Petruzzi y otros vs. Perü". Disponible en http://www. corteidh.or.cr/docs/casos/articulos/seriec_52_esp.pdf [fecha de visita 22 de diciembre de 2014] p. 44.

- Sentencia Corte Suprema. 30 de enero de 2014. Rol: 669-2013. Recurso de casación en la forma y en el fondo en causa "Paredes Ortega, Maria con Merino Paredes, Daniela Patricia". Disponible en http://suprema.poderjudicial.cl/SITSUPPORWEB/InicioAplicacion. do [fecha de visita 23 de diciembre de 2014]

- Sentencia Corte Suprema. 9 de diciembre de 2013. Rol: $9252-$ 2012. Recurso de casación en la forma y en el fondo en causa " $A d m$. de Inv. y Sup. Unimarc S.A. con Empresa de Servicios Sanitarios del Bio Bio S.A., Interagro Comercio y Ganado S.A.”.

- Sentencia Corte Suprema. 17 de marzo de 2014. Rol 107662013. Recurso de casación en la forma y en el fondo en causa "Santander Asset Management con Comercial e Inversiones Atlántida S.A. y otro". Disponible en http://suprema.poderjudicial.cl/ SITSUPPORWEB/InicioAplicacion.do [fecha de visita 23 de diciembre de 2014].

- Sentencia Corte Suprema. 5 de marzo de 2014. ROL 59672013. Recurso de unificación de jurisprudencia en materia laboral 
"Andrade con Ministerio Publico". Disponible en http://suprema. poderjudicial.cl/SITSUPPORWEB/InicioAplicacion.do [fecha de visita 23 de diciembre de 2014].

- Sentencia Corte Suprema. 15 de octubre de 2013. ROl 2688-2012. Recurso de casación en el fondo "Sociedad Agrícola Vásquez Ltda. con Fisco de Chile". Disponible en http://suprema. poderjudicial.cl/SITSUPPORWEB/InicioAplicacion.do [fecha de visita 23 de diciembre de 2014].

- Sentencia Corte Suprema. 9 de octubre de 1964. Recurso de casación en la forma y en el fondo en causa "Contreras con Gouet": Corte Suprema, Revista de Derecho y Jurisprudencia (1964), tomo 61, $2^{\text {a }}$ parte, sección $1^{\circ}$, pp. 310-313.

- Sentencia Tribunal Constitucional de España 64/1997, 7 de abril de 1997. Boletín Oficial del Estado núm. 114 de 13 de mayo de 1997, pp. 15 a 20.

- Sentencia Tribunal Constitucional de España 69/2001, 17 de marzo de 2001. Boletín Oficial del Estado núm. 83 de 6 de abril de 2001, pp. 77 a 112.

- Sentencia Tribunal Constitucional de España 37/2013, 14 de febrero de 2013. Boletín Oficial del Estado num. 61 de 12 de marzo de 2013, pp. 145 a 155. 